\title{
Synaptic State-Dependent Functional Interplay between Postsynaptic Density-95 and Synapse-Associated Protein 102
}

\author{
Stéphanie A. D. Bonnet, ${ }^{1,2,3 *}$ Derya S. Akad, ${ }^{1,2,4 \star}$ Tanmoy Samaddar, ${ }^{1,3}$ Yanling Liu, ${ }^{1}$ Xiaojie Huang, ${ }^{1,3}$ Yan Dong, ${ }^{5}$ \\ and Oliver M. Schlüter ${ }^{1,2}$ \\ ${ }^{1}$ Molecular Neurobiology and ${ }^{2}$ Cluster of Excellence "Nanoscale Microscopy and Molecular Physiology of the Brain," European Neuroscience Institute, \\ D-37077 Göttingen, Germany, ${ }^{3}$ Göttingen Graduate School for Neurosciences and Molecular Biosciences, D-37077 Göttingen, Germany, ${ }^{4}$ International Max \\ Planck Research School for Neuroscience, D-37077 Göttingen, Germany, and ${ }^{5}$ Department of Neuroscience, University of Pittsburgh, Pittsburgh, \\ Pennsylvania 15260
}

Activity-dependent regulation of AMPA receptor (AMPAR)-mediated synaptic transmission is the basis for establishing differences in synaptic weights among individual synapses during developmental and experience-dependent synaptic plasticity. Synaptic signaling scaffolds of the Discs large (DLG)-membrane-associated guanylate kinase (MAGUK) protein family regulate these processes by tethering signaling proteins to receptor complexes. Using a molecular replacement strategy with RNAi-mediated knockdown in rat and mouse hippocampal organotypic slice cultures, a postsynaptic density-95 (PSD-95) knock-out mouse line and electrophysiological analysis, our current study identified a functional interplay between two paralogs, PSD-95 and synapse-associated protein 102 (SAP102) to regulate synaptic AMPARs. During synaptic development, the SAP102 protein levels normally plateau but double if PSD-95 expression is prevented during synaptogenesis. For an autonomous function of PSD-95 in regulating synaptic AMPARs, in addition to the previously demonstrated N-terminal multimerization and the first two PDZ (PSD-95, Dlg1, zona occludens-1) domains, the PDZ3 and guanylate kinase domains were required. The Src homology 3 domain was dispensable for the PSD-95-autonomous regulation of basal synaptic transmission. However, it mediated the functional interaction with SAP102 of PSD-95 mutants to enhance AMPARs. These results depict a protein domain-based multifunctional aspect of PSD-95 in regulating excitatory synaptic transmission and unveil a novel form of domain-based interplay between signaling scaffolds of the DLG-MAGUK family.

\section{Introduction}

Regulation of AMPA receptor (AMPAR)-mediated synaptic transmission is critical for shaping neuronal networks during developmental plasticity and learning and memory (Malenka and Bear, 2004; Kerchner and Nicoll, 2008; Neves et al., 2008). The trafficking of AMPARs at synapses is regulated by various proteins, including signaling scaffolds of the Discs large (DLG)membrane-associated guanylate kinase (MAGUK) family (Elias and Nicoll, 2007; Xu, 2011). Postsynaptic density-93 (PSD-93),

Received Dec. 16, 2011; revised June 11, 2013; accepted July 3, 2013.

Author contributions: S.A.D.B., D.S.A., Y.D., and O.M.S. designed research; S.A.D.B., D.S.A., T.S., Y.L., X.H., and 0.M.S. performed research; S.A.D.B., D.S.A., T.S., Y.L., Y.D., and 0.M.S. analyzed data; S.A.D.B., D.S.A., Y.D., and O.M.S. wrote the paper.

This work was supported by the German Research Foundation through the Cluster of Excellence "Nanoscale Microscopy and Molecular Physiology of the Brain," the Collaborative Research Center 889 "Cellular Mechanisms of Sensory Processing," German Research Foundation Grant SCHL592/4, the European Commission through the Marie Curie initial training network SyMBaD ("Synapses: From Molecules to Higher Brain Function and Diseases") (0.M.S.), and the Alexander von Humboldt Foundation (Y.D.). This work was also partially supported by National Institutes of Health/National Institute on Drug Abuse Grants DA030379, DA023206, DA031551, and DA034856 (Y.D.). We thank S. Ott-Gebauer and M. Bremer for excellent technical assistance and Drs. S. Grant and D. Bredt for mouse lines. The European Neuroscience Institute Göttingen is jointly funded by the Göttingen University Medical School and the Max Planck Society.

*S.A.D.B. and D.S.A. contributed equally to this work.

Correspondence should be addressed to Oliver M. Schlüter, European Neuroscience Institute, Grisebachstrasse 5, D-37077 Göttingen, Germany. E-mail: oschlue@gwdg.de.

DOI:10.1523/JNEUROSCI.6255-11.2013

Copyright $\odot 2013$ the authors $\quad 0270-6474 / 13 / 3313398-12 \$ 15.00 / 0$
PSD-95, synapse-associated protein 97 (SAP97), and SAP102 constitute the DLG-MAGUK family. They share three consecutive PDZ domains, followed by an Src homology 3 (SH3) and a guanylate kinase (GK) domain, which mediate the specific interactions of the DLG-MAGUKs (Kim and Sheng, 2004).

The N-terminally palmitoylated $\alpha$ isoform of PSD-95 is the most abundant DLG-MAGUK in the postsynaptic density (PSD) of forebrain neurons (Chetkovich et al., 2002; Peng et al., 2004; Chen et al., 2005; Cheng et al., 2006; Dosemeci et al., 2007). Its abundance is directly correlated with the strength of AMPARmediated synaptic transmission. Overexpression of PSD-95 increases AMPAR function (Schnell et al., 2002; Béique and Andrade, 2003; Ehrlich and Malinow, 2004), whereas RNAimediated knockdown or genetic deletion of PSD-95 reduces it (Nakagawa et al., 2004; Béique et al., 2006; Elias et al., 2006; Schlüter et al., 2006; Carlisle et al., 2008). PSD-95 interacts with the AMPAR auxiliary subunits of the transmembrane AMPARassociated protein family, an interaction that is required for overexpressed PSD-95 to enhance AMPAR function (Chen et al., 2000; Schnell et al., 2002; Sumioka et al., 2011). Furthermore, N-terminal multimerization of PSD-95 is required to enhance AMPARs (Xu et al., 2008). This multimerization enables C-terminally truncated constructs of PSD-95 to assemble with endogenous PSD-95, resulting in an enhancement of AMPAR function to the same degree as overexpression of full-length PSD95. By this means, expression of a recombinant PSD-95 only 
containing the N-terminal domain and the first two PDZ domains is sufficient to enhance AMPAR function similar to the full-length PSD-95 in the presence of endogenous PSD-95 (Schnell et al., 2002). However, when expressed in the absence of endogenous PSD-95, expression of this construct or another one that contains additionally the third PDZ domain does not affect AMPAR function (Xu et al., 2008). A critical question is which C-terminal domain is additionally required to form a minimal PSD-95 (containing the minimal number of domains) that can regulate AMPARs in basal synaptic transmission. Deleting the C-terminal GK domain or $\mathrm{SH} 3$ domain does not prevent the function of these mutant PSD-95 to enhance AMPAR function (Jo et al., 2010). However, deleting both domains does (Xu et al., 2008). Thus, another critical question is whether these two domains share functional redundancy or other mechanisms are involved.

Using the molecular replacement technique (Schlüter et al., 2006), here we dissected the domains of PSD-95 to identify the minimal PSD-95, which can regulate AMPAR function in basal synaptic transmission autonomously. We identified different domains with permissive and essential roles in PSD-95 function on AMPARs. Furthermore, we identified a developmental and functional interplay between PSD-95 and SAP102 to regulate AMPARs. These results provide additional but essential knowledge in understanding the multifaceted synaptic functions of PSD-95 and other related MAGUKs.

\section{Materials and Methods}

Hippocampal organotypic slices cultures. Organotypic slice cultures were made as described previously (Schlüter et al., 2006). Briefly, the hippocampi from postnatal day 8 (P8) rats or mice of either sex were dissected in ice-cold sucrose cutting buffer (in mM: 204 sucrose, 26 $\mathrm{NaHCO}_{3}, 10$ D-glucose, $2.5 \mathrm{KCl}, 1 \mathrm{NaH}_{2} \mathrm{PO}_{4}, 4 \mathrm{MgSO}_{4}, 1 \mathrm{CaCl}_{2}$, and 4 $\mathrm{L}$-ascorbic acid; sterile filtered) from the isoflurane-anesthetized animals. Three-hundred-micrometer hippocampal transversal slices were cut with a custom-made guillotine and then held for $30 \mathrm{~min}$ at room temperature $\left(\sim 22^{\circ} \mathrm{C}\right)$ in ASCF [in mM: $119 \mathrm{NaCl}, 26 \mathrm{NaHCO}_{3}, 20$ D-glucose, $2.5 \mathrm{KCl}, 1 \mathrm{NaH}_{2} \mathrm{PO}_{4}, 4 \mathrm{MgSO}_{4}$, and $4 \mathrm{CaCl}_{2}$ (sterilely filtered and oxygenated for $30 \mathrm{~min}$ with $95 \% \mathrm{O}_{2} / 5 \% \mathrm{CO}_{2}$ before use)]. Before plating the slices onto a MilliCell Culture Plate Inserts (Millipore), they were washed in ice-cold basal medium Eagle (BME) (Biochrom) supplemented with 7 $\mathrm{mm} \mathrm{MgCl}_{2}$. During the first day of culture, slices were kept at $37^{\circ} \mathrm{C}$ and then transferred to a $34^{\circ} \mathrm{C}$ incubator for the remaining culturing time. The culture media contained 49\% BME, 25\% Earle's balanced salt solution (EBSS), $25 \mathrm{~mm}$ HEPES, 20\% horse serum (heat inactivated for 30 $\mathrm{min}$ at $55^{\circ} \mathrm{C}$; HyClone or Biochrom), $28 \mathrm{~mm}$ D-glucose, $1 \mathrm{~mm}$ Glutamax (Invitrogen), $88 \mu \mathrm{g} / \mathrm{ml} \mathrm{L}$-ascorbic acid, $1 \mu \mathrm{g} / \mathrm{ml}$ insulin, $0.25 \% 100 \times$ Minimum Essential Medium (MEM)-vitamins, and 0.49\% 50× MEMamino acids. The media was changed the day after culturing as well as the day of lentivirus injection. After $3 \mathrm{~d}$ in vitro (DIV), culture media was substituted with a feeding media containing 63.3\% BME, 25\% EBSS, 25 mM HEPES, 5\% horse serum (heat-inactivated), $28 \mathrm{~mm}$ D-glucose, $2 \mathrm{~mm}$ Glutamax, $88 \mu \mathrm{g} / \mathrm{ml} \mathrm{L}$-ascorbic acid, $1 \mu \mathrm{g} / \mathrm{ml}$ insulin, $0.32 \% 100 \times$ MEM-vitamins, and 0.63\% 50× MEM-amino acids. During DIV5DIV10, slices were used for electrophysiological recordings. During this period, the feeding media was changed every other day.

Electrophysiology. For dual whole-cell patch-clamp recordings, the slices were transferred into a heated $\left(\sim 30^{\circ} \mathrm{C}\right)$ submerged recording chamber, continuously perfused $(2-3 \mathrm{ml} / \mathrm{min})$ with carbogenated $(95 \%$ $\mathrm{O}_{2}, 5 \% \mathrm{CO}_{2}$ ) artificial CSF (ACSF). One to $5 \mu \mathrm{M}$ 2-chloroadenosine was added to reduce polysynaptic activity and $50 \mu \mathrm{M}$ picrotoxin to block inhibitory transmission for isolation of EPSCs. Constant $(0.2 \mathrm{~Hz})$ extracellular stimulation of the Schaffer collaterals by brief $(0.2 \mathrm{~ms})$ current pulses via a bipolar theta glass electrode (filled with ACSF) elicited EPSCs at the postsynaptic site. These EPSCs were recorded by somatic dual whole-cell voltage-clamp recordings using a 2-4 $\mathrm{M} \Omega$ glass electrode filled with internal recording solution (in mm: $117.5 \mathrm{MeSO}_{3} \mathrm{H}, 10$ HEPES, $17.75 \mathrm{CsCl}, 10$ TEA-Cl, 0.25 EGTA, 10 D-glucose, $2 \mathrm{MgCl}_{2}, 4$ $\mathrm{Na}_{2} \mathrm{ATP}$, and $\left.0.3 \mathrm{NaGTP}\right)$. $\mathrm{CsOH}(50 \%$, w/v) was used to adjust $\mathrm{pH}$ to 7.3 , and the solution was cooled to $4^{\circ} \mathrm{C}$ before adding $\mathrm{Na}_{2} \mathrm{ATP}$ and $\mathrm{NaGTP}$. The osmolarity was adjusted to $290 \mathrm{mOsm}$ with CsCl. The solution was filtered with a $0.2 \mu \mathrm{m}$ syringe filter, aliquoted, and stored at $-80^{\circ} \mathrm{C}$ for up to 3 months). A minimum of 40 sweeps was collected from each pair of neurons (one virally transduced and the other control) using an Axopatch 700B amplifier (Molecular Devices), an ITC18 (HEKA) analog-to-digital converter, and customized acquisition software in IGOR Pro (Wavemetrics). Series and input resistances were monitored by a $5 \mathrm{mV}$ hyperpolarizing step pulse before each sweep. Neurons presenting $>25 \%$ variation in the series resistance or higher than $20 \mathrm{M} \Omega$ of input resistance were excluded from experiments. AMPA and NMDA components were isolated by voltage clamping neurons at -60 and +40 $\mathrm{mV}$, respectively. AMPAR EPSC was measured at the peak amplitude, whereas the NMDA receptor (NMDAR) component was operationally measured as the amplitude of the current $60 \mathrm{~ms}$ after the onset of the EPSC (a time point at which the rapid AMPAR component has mostly decreased to the baseline).

DNA constructs. All recombinant PSD-95 mutant constructs were C-terminally tagged with eGFP (Schlüter et al., 2006; Xu et al., 2008). The sequences of the shRNA against rat PSD-95 as well as the molecular replacement vector, including the full-length recombinant PSD-95 and PDZ1/2::GFP and the PDZ1/2::GFP overexpression construct, were made as described previously (Schlüter et al., 2006; Xu et al., 2008). The SAP102 shRNA (sh102) and SAP97 shRNA (sh97) sequences were as follows: CCCTGGGTTAAGTGACGATTACTCGAGTAATCGTCACTT AACCCAGGGTT and GCATCTGTTGGAAGAATATTTCAAGAGAAT ATTCTTCCAACAGATGCTT, respectively. They were expressed from an RNA Pol III (U6) promoter. The shRNA against mouse PSD-95 was TCACGATCATCGCTCAGTATATAGTGAAGCCACAGATGTATATA CTGAGCGATGATCGTGA, embedded in a miR30 backbone, and expressed from an RNA Pol III (hH1) promoter (Stegmeier et al., 2005).

To generate replacement or overexpression constructs lacking single or multiple domains of interest, the PSD-95 mutant constructs were shuttled into FHsh95UG + W or FUGW between XbaI and BsrGI restriction sites, respectively. Domain deletion mutants were generated by PCR, introducing in-frame restriction site, and consisted of the following amino acids of the 724 full-length rat PSD-95: PSD-95 PDZ3 (amino acids 1-309, "NheI-HinDIII," amino acids 430-724), PSD-95 SSH3 (amino acids 1-427, "EcoRV," amino acids 499-724), PSD-95 GK (amino acids 1-502 and 699724), PSD-95-PDZ1/2-GK (amino acids 1-263, "BstBI," amino acids 499724), and PSD-95-PDZ1/2-SH3 (amino acids 1-309, "NheI-HinDIII," amino acids 430-502 and 699-724).

Mouse lines. PSD-95 knock-out (KO) mice were bred from heterozygous parents and genotyped by PCR with a band at 255 bp for the wildtype (WT) allele and $355 \mathrm{bp}$ for the KO allele using the following primers: CAGGTGCTGCTGGAAGAAGG versus CTACCCTGTGATCCAGAG CTG (Yao et al., 2004).

Dissociated neuronal cultures. Dissociated hippocampal and cortical neuronal cultures were prepared from P0 or P1 mice or Wistar rats of either sex. The intended brain regions were dissected and digested for 30 min at $37^{\circ} \mathrm{C}$ with papain, as described previously (Huettner and Baughman, 1986; Schlüter et al., 2006). Approximately $10^{5}$ cells per well in a 24 -well plate and $\sim 10^{6}$ cells per well in a six-well plate were plated into DMEM/Ham's F-12 (Biochrom), supplemented with 2\% B27 (Invitrogen) and $1 \%$ Glutamax (Biochrom) on a poly-D-lysine-coated plates. Glial growth was inhibited by adding fluorodeoxyuridine $(0.01 \mathrm{mg} / \mathrm{ml})$ at DIV4. The cells were re-fed every 3-7 d with the astrocyte-conditioned culture medium.

Subcellular fractionation of cortical cultures. After washing neurons with ice-cold PBS, cells were collected in the homogenization buffer (4 mM HEPES/NaOH, pH7.4, 320 mm sucrose) and homogenized in a Balch homogenizer with $10 \mu \mathrm{m}$ spacing (Balch and Rothman, 1985). Cell debris was removed by a 15 -min $1000 \times g$ centrifugation; the supernatant was then fractionated with a $20-\min 10,000 \times g$ centrifugation into the supernatant (cytosol and microsomal fraction S2) and pellet (crude synaptosomes P2) fractions. The P2 fraction was lysed in resuspension buf- 
fer $(150 \mathrm{~mm} \mathrm{KCl})$, supplemented with $1 \%$ Triton X-100 (G Biosciences), and fractionated with a 3 -h $200,000 \times g$ centrifugation into the Triton $\mathrm{X}-100$-soluble (1T-S) and -insoluble (1T-P) fraction. All fractions were dissolved in $1 \%$ SDS for protein concentration measurements, and the protein concentrations were adjusted to 0.5 or $1 \mu \mathrm{g} / \mu \mathrm{l}$ in SDS sample buffer.

Subcellular fractionation of mouse brain. Subcellular fractions with enriched PSD from PSD-93 KO, PSD-95 KO, and littermate WT control mice of either sex were prepared as described previously (Cho et al., 1992; Schlüter et al., 1999). One mouse cortex was homogenized in $10 \mathrm{ml}$ of homogenization buffer. A crude synaptosomal pellet (P2) was isolated by differential centrifugation and was resuspended in a resuspension buffer [50 mm NaF, 50 mm HEPES/NaOH, pH 7.4, 1 mm EDTA, $0.2 \mathrm{~mm} \mathrm{NaVO}_{4}$, and $1 \mu \mathrm{g} / \mu \mathrm{l}$ complete protease inhibitors (Roche)]. Samples were extracted with $0.5 \%$ Triton X-100 for $15 \mathrm{~min}$ and then were centrifuged 20 min at $32,000 \times g$ to obtain the Triton X-100-insoluble (1T-P) and -soluble (1T-S) fraction. The pellet was resuspended in half of the previous volume of the resuspension buffer and extracted in 3\% $\mathrm{N}$-lauroylsarcosine for $10 \mathrm{~min}$. The extract was centrifuged for $1 \mathrm{~h}$ at $200,000 \times g$ to obtain the $N$-lauroylsarcosine-insoluble (TSP) and -soluble PSD fraction. All fractions were protected against proteolysis with $1 \%$ SDS and adjusted to $1 \mu \mathrm{g} / \mu \mathrm{l}$ in the SDS sample buffer.

Antibodies and quantitative Western blotting. Ten to $30 \mu \mathrm{g}$ of protein were separated on Bis-Tris polyacrylamide gels and transferred on nitrocellulose membranes (Schlüter et al., 1999). Protein bands were decorated with the following primary antibodies: GluN2B, SAP97, SAP102, PSD-93, PSD-95, mortalin (mouse; University of California, Davis/National Institutes of Health NeuroMab), GluN1, Rab3A, Synaptophysin (mouse; Synaptic Systems), Stargazin, GluN2A, GluA1 (rabbit; Millipore), and GDP dissociation inhibitor (GDI) (Schlüter et al., 1999). Bands were detected by the secondary antibodies goat anti-mouse Alexa Fluor 680 (Invitrogen), goat anti-rabbit Alexa Fluor 680 (Invitrogen), goat anti-mouse IR800 (LI-COR Biosciences), and goat anti-rabbit IR800 (LI-COR Biosciences) and visualized and quantified with an infrared fluorescence scanner.

Data presentation and statistics. All electrophysiological data were recorded from slice cultures of at least two animals and are presented as mean \pm SEM (error bars). Statistical significance of data was determined using two-tail paired $t$ test for the comparison between the control and infected cells. The $p$ value $<0.05$ was considered statistically significant. Sample size $n$ refers to the number of cells/pairs (maximum of two cell pairs per slice). Ratios between cell pairs were averaged after log transformation and presented as the back-transformed mean \pm SEM. Protein quantifications were presented as normalized means \pm SEM to WT samples, in which $n$ represents the number of animals. One-way ANOVA with Tukey's post hoc tests was used to calculate significant differences.

\section{Results}

PSD-95 regulates basal excitatory synaptic transmission by autonomously enhancing AMPAR function (Elias and Nicoll, 2007; $\mathrm{Xu}, 2011)$. Knockdown of PSD-95 in rat organotypic hippocampal slice cultures reduces AMPAR EPSCs by $50 \%$ but has no or a smaller effect on NMDAR EPSCs (Nakagawa et al., 2004; Elias et al., 2006; Schlüter et al., 2006). Conversely, molecularly replacing the endogenous PSD-95 with GFP-tagged full-length PSD-95, which causes a net increase in the synaptic levels of PSD-95, increases AMPAR EPSCs twofold to threefold (Schlüter et al., 2006; $\mathrm{Xu}$ et al., 2008). In the current study, the synaptic effects of knockdown and full-length replacement served as two reference endpoints to measure the regulatory efficacies of PSD-95 constructs with domain mutations. To examine whether the mutant PSD-95s corroborated the overall structure of PSD-95, the constructs were also overexpressed without the shRNA targeting PSD-95 (sh95). In this case, a minimal PSD-95, consisting of the $\mathrm{N}$ terminus with the first two PDZ domains, has been shown to be sufficient to enhance AMPAR EPSCs, similar to the full length PSD-95 (Schnell et al., 2002; Xu et al., 2008).

To establish the reference points in our experimental conditions, we used rat organotypic hippocampal slice cultures 5-10 d after lentiviral transduction with a viral construct expressing sh95 only or sh95 with full-length recombinant PSD-95, fused to GFP (rPSD-95). Dual whole-cell patch-clamp recordings were made from a transduced CA1 pyramidal neuron and a neighboring control one, with the same presynaptic stimulation electrode placed on Schaffer collateral fibers. With this dual recording setup, we observed a $>45 \%$ reduction of the AMPAR EPSCs (at $-60 \mathrm{mV}$ ) in sh95-expressing neurons (sh95, $-54.4 \pm 7.6 \mathrm{pA}$ vs control, $-92.7 \pm 9.6 \mathrm{pA}, n=38, p<0.001$; Fig. $1 A, D)$ and a twofold increase in neurons with the full-length PSD-95 replacement $($ sh95 + rPSD-95, $-83.0 \pm 13.5$ pA vs control, $-43.0 \pm 9.5$ pA, $n=25, p<0.01$; Fig. $1 B, D)$. No significant change was observed in NMDAR EPSC (at $+40 \mathrm{mV}$ ) in sh95-expressing neurons $(\operatorname{sh} 95,57.6 \pm 6.9 \mathrm{pA}$ vs control, $60.0 \pm 6.7 \mathrm{pA}, n=38, p=$ 0.59 ), but a $\sim 20 \%$ increase was observed in neurons with the rPSD-95 replacement ( $\mathrm{sh} 95+$ rPSD-95, 58.0 \pm 8.0 pA vs control, $41.4 \pm 7.5 \mathrm{pA}, n=25, p<0.05)$.

Replacing endogenous PSD-95 with overexpression of the $\mathrm{N}$-terminal domain of PSD-95, including the first two PDZ domains $(\mathrm{PDZ1} / 2)$, resulted in a $45 \%$ reduction of the AMPAR EPSC (sh95 + PDZ1/2, $-30.3 \pm 5.6$ pA vs control, $-47.1 \pm 7.1$ pA, $n=14, p<0.01$; Fig. $1 C, D)$ and no significant change in NMDAR EPSCs $(\operatorname{sh} 95+$ PDZ1/2, $26.9 \pm 4.9$ pA vs control, $34.3 \pm 6.7 \mathrm{pA}, n=14, p=0.09$ ). Thus, expressions of sh95 and sh95 + PDZ1/2 are functionally equivalent, suggesting that the $\mathrm{N}$-terminal domain does not autonomously regulate AMPAR EPSCs, as shown previously (Xu et al., 2008).

\section{Selective requirements of single domains of PSD-95 for enhancing AMPAR function}

The $\mathrm{N}$ terminus including the first two PDZ domains is essential to enhance AMPAR function; PSD-95 without $\mathrm{N}$ terminus does not target to synapses and does not affect AMPARs (Craven et al., 1999; Schnell et al., 2002). Thus, we tested which of the remaining three domains, PDZ3, SH3, and GK, is dispensable in PSD-95 for its autonomously enhancing effects on AMPARs. Replacing the endogenous PSD-95 by overexpression of a PSD-95 construct lacking the $\mathrm{SH} 3$ domain (p95 $\Delta \mathrm{SH} 3$ ) increased the peak amplitudes of AMPAR EPSCs by twofold ( $\operatorname{sh} 95+$ p95 $\Delta \mathrm{SH} 3,-64.9 \pm$ $8.2 \mathrm{pA}$ vs control, $-33.4 \pm 4.6 \mathrm{pA}, n=32, p<0.01$; Fig. $2 A, D)$ and NMDAR EPSCs by $\sim 30 \%(\operatorname{sh} 95+$ p $95 \Delta$ SH3, $66.8 \pm 10.2 \mathrm{pA}$ vs control, $49.5 \pm 7.7 \mathrm{pA}, n=32, p<0.01)$. The patterns and magnitudes of the effect of this replacement were similar to that of rPSD-95 replacement (Fig. $1 B$ ), suggesting that the SH3 domain is functionally dispensable for PSD-95 to enhance AMPAR EPSCs in basal synaptic transmission.

In contrast, replacing endogenous PSD-95 by overexpression of a PSD-95 construct lacking the PDZ3 domain (p95 PDZ3) did not significantly affect AMPAR EPSCs (sh95 + p95 $\triangle$ PDZ3, $-103.4 \pm 9.3 \mathrm{pA}$ vs control, $-93.0 \pm 8.8 \mathrm{pA}, n=22, p=0.22$; Fig. $2 B, D)$ and NMDAR EPSCs $(\operatorname{sh} 95+$ p95 2 PDZ3, $66.0 \pm 6.0$ $\mathrm{pA}$ vs control, $70.0 \pm 6.5 \mathrm{pA}, n=22, p=0.55)$. Similarly, expression of a construct lacking the GK domain (p95 $\Delta \mathrm{GK})$ also did not significantly affect either AMPARs $(\operatorname{sh} 95+$ p95 $\Delta$ GK, $-65.8 \pm$ $6.7 \mathrm{pA}$ vs control, $-55.4 \pm 5.1 \mathrm{pA}, n=20, p=0.14$; Fig. $2 C, D)$ or NMDARs ( sh95 + p95 $\Delta$ GK, $45.6 \pm 4.2 \mathrm{pA}$ vs control, $49.9 \pm 3.5$ $\mathrm{pA}, n=32, p=0.09)$. Thus, unlike either the replacement with the p95 $\triangle \mathrm{PDZ1} / 2$ construct, which decreased AMPAR function (Fig. 1C), or the replacement with full-length rPSD-95, which 
A

$\operatorname{sh} 95$

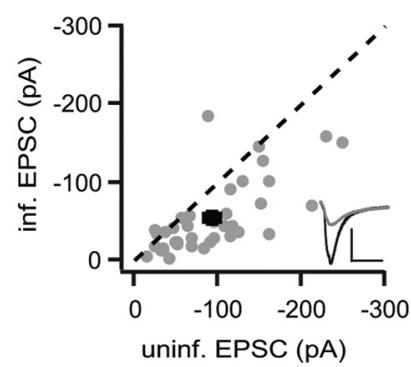

C

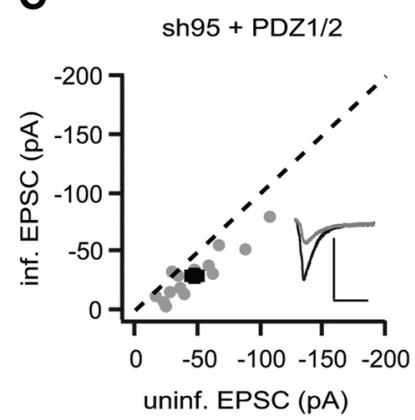

B $\quad$ sh95 + PSD-95

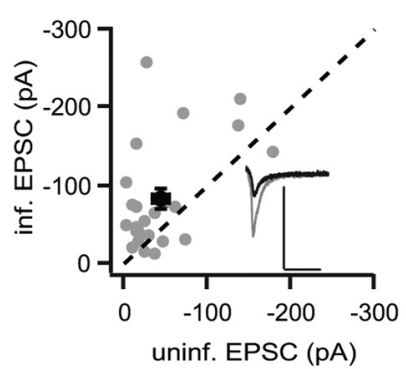

D

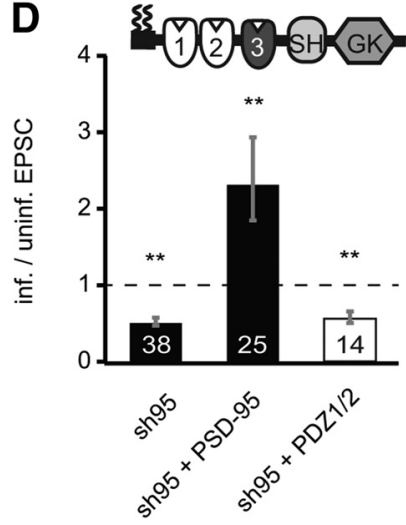

A

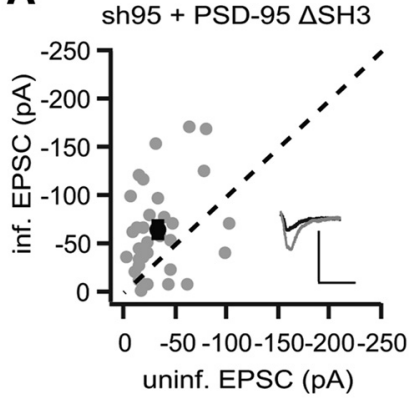

C

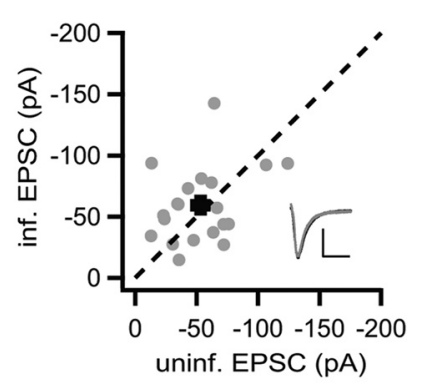

B
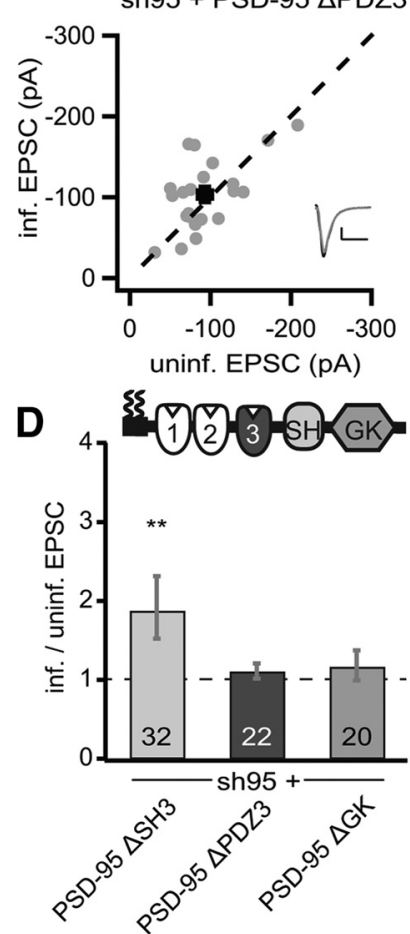

Figure 1. The protein levels of PSD-95 were correlated with the strength of AMPAR EPSCS. $\boldsymbol{A}-\boldsymbol{C}$, Amplitude peaks of AMPAR EPSCs of neurons expressing sh95 (A), sh95 + rPSD-95 (B), or sh95 + PDZ1/2 (C) were plotted against those of simultaneously recorded uninfected neighboring neurons in rat hippocampal slice cultures. [In this and all subsequent panels, gray symbols represent single pairs of recordings, and black symbols show mean \pm SEM. $p$ values were calculated with a paired Student's $t$ test comparing absolute values of paired recordings. Insets in each panel show representative EPSC trace of averaged 30 sweeps for control (black) and infected neuron (gray). Calibration: 50 pA, 25 ms.] D, Summary of AMPAR EPSC ratio of infected and uninfected pairs. Schematic representation of PSD-95 with color-coded domains, matching the bar colors. Number of pairs $(n)$ indicated in the foot of the graph. Statistical significance is indicated with asterisks from the analysis in $\boldsymbol{A}-\boldsymbol{C}$ to indicate difference from control.

increased AMPAR function (Fig. 1B), the replacement with p95 9 PDZ3 or p95 $\Delta$ GK produced an intermediate effect, suggesting that these PSD-95 mutants preserved partial function of the full-length rPSD95.

To better understand these partial effects, we focused first on p95 $\Delta \mathrm{GK}$, because the GK domain binds to guanylate kinase domain-associated protein (GKAP) and thus links PSD-95 to the deeper layers of the PSD (Kim et al., 1997). We first overexpressed p95 $\Delta$ GK without replacing endogenous PSD-95. This manipulation increased the peak amplitudes of AMPAR EPSCs more than twofold (p95 $\Delta \mathrm{GK},-74.4 \pm 12.0 \mathrm{pA}$ vs control, $-32.2 \pm 5.3 \mathrm{pA}, n=14, p<0.01$; Fig. $3 A, C$ ), whereas the NMDAR EPSCs were not significantly affected (p95 $\Delta \mathrm{GK}, 32.4 \pm$ $5.7 \mathrm{pA}$ vs control, $24.9 \pm 5.0 \mathrm{pA}, n=14, p=0.16$ ). These effects were similar to overexpression of full-length rPSD-95 (in the presence of endogenous PSD-95), which also increased the peak amplitudes of AMPAR EPSCs by more than twofold (rPSD-95, $-165.9 \pm 19.9 \mathrm{pA}$ vs control, $68.7 \pm 9.1 \mathrm{pA}, n=23$, $p<0.01$; Fig. $3 B, C$ ) without affecting NMDAR EPSCs (rPSD$95,102.2 \pm 14.9 \mathrm{pA}$ vs control, $75.4 \pm 9.3 \mathrm{pA}, n=23, p=$ $0.06)$. This result indicated that the p $95 \Delta \mathrm{GK}$ mutant possessed the capacity as full-length rPSD-95 in enhancing AMPAR function but requires certain forms of interactions with endogenous PSD-95 or other signaling proteins to be fully functional.

Figure 2. The SH3 domain was not required for PSD-95 to enhance AMPAR EPSCs. $\boldsymbol{A}-\boldsymbol{C}$, Amplitude peaks of AMPAR EPSCs of neurons expressing sh95 + p95 $\Delta$ SH3 $(\boldsymbol{A})$, sh95 + p95 $\Delta$ PDZ3 $(\boldsymbol{B})$, or sh95 + p95 $\Delta$ GK $(\boldsymbol{C})$ were plotted against those of simultaneously recorded uninfected neighboring neurons in rat hippocampal slice cultures. $D$, Summary of AMPAR EPSC ratio of infected and uninfected pairs. Schematic representation of PSD-95 with color-coded domains, matching the bar colors. Number of pairs $(n)$ indicated in the foot of the graph. Statistical significance is indicated with asterisks from the analysis in $\boldsymbol{A}-\boldsymbol{C}$ to indicate difference from control. Calibration: $50 \mathrm{pA}, 25 \mathrm{~ms}$.

When SAP97 $\beta$ is substituted for endogenous PSD-95, AMPAR EPSCs are rescued to the control cell levels (Schlüter et al., 2006), an intermediate effect similar to the effects of p95 PPDZ3 and p95 $\Delta \mathrm{GK}$. Furthermore, the effect of PSD-95-to-SAP97 $\beta$ replacement on AMPARs is bidirectionally regulated by the basal activity of the neuron; it is inhibited by the NMDAR antagonist $\mathrm{APV}$ and enhanced by increasing the excitatory activity in the slice cultures with the $\mathrm{GABA}_{\mathrm{A}}$ receptor $\left(\mathrm{GABA}_{\mathrm{A}} \mathrm{R}\right)$ antagonist bicucculline (bic) (Abegg et al., 2004; Schlüter et al., 2006). We tested whether the effect of PSD-95-to-p95 $\Delta$ GK replacement was also modulated by the basal neuronal activity by manipulating the basal activity of NMDARs and $\mathrm{GABA}_{\mathrm{A}} \mathrm{Rs}$. However, incubation (5-7 d) of neither bic $(20 \mu \mathrm{M})$ nor APV $(25 \mu \mathrm{M})$ altered the effect of p95 $\Delta \mathrm{GK}$ replacement on AMPAR EPSCs [p95 $\Delta \mathrm{GK}$ (bic), $-70.3 \pm 14.0 \mathrm{pA}$ vs control, $-52.9 \pm 6.9 \mathrm{pA}, n=11, p=$ 0.28 ; p95 $\Delta \mathrm{GK}$ (APV), $-33.3 \pm 3.6 \mathrm{pA}$ vs control, $-29.2 \pm 3.4$ $\mathrm{pA}, n=18, p=0.38]$. NMDAR EPSCs were not significantly changed in any of these conditions [p95 $\Delta \mathrm{GK}$ (bic), $27.1 \pm 4.7 \mathrm{pA}$ vs control, $30.7 \pm 6.0 \mathrm{pA}, n=11, p=0.43$; p95 $\Delta \mathrm{GK}$ (APV), $35.4 \pm 5.1 \mathrm{pA}$ vs control, $30.8 \pm 4.3 \mathrm{pA}, n=21, p=0.22]$.

\section{Differential effects of p95 $\Delta \mathrm{GK}$ in rat and mouse neurons}

The replacement approach involves RNAi-based gene knockdown, which substantially decreases but does not completely remove endogenous PSD-95 (Schlüter et al., 2006). Thus, some residual endogenous PSD-95 may confound the experimental results. To address this caveat, we prepared organotypic hippocampal slice 
cultures using P8 PSD-95 KO mice (Yao et al., 2004). CA1 pyramidal cells were then transduced with the same lentiviral constructs as in the above rat experiments. We first tested the two reference constructs. PDZ1/2 did not change AMPAR EPSCs or NMDAR EPSCs significantly $(\mathrm{PDZ} 1 / 2$ AMPAR, $-66.6 \pm 14.4 \mathrm{pA}$ vs control, $-70.6 \pm 12.0 \mathrm{pA}, n=12, p=$ 0.63 ; NMDAR, $100.0 \pm 17.9$ pA vs control, $110.6 \pm 20.9 \mathrm{pA}, n=12, p=0.25$; Fig. $4 B, D)$. Thus, similar to that in rat slice cultures (Fig. 1), PDZ1/2 has no autonomous effect on AMPARs. Note that, although the reference cell in the rat slice culture is a WT neuron, in the PSD-95 KO slice culture, it is a PSD-95-lacking neuron. Hence, in rat slice cultures, the $\mathrm{PDZ} 1 / 2$ did not rescue the reduced AMPAR EPSCs caused by the sh95, whereas in PSD-95 KO neurons, both the reference and the manipulated neuron were both lacking endogenous PSD-95. Similar to that in rat slice cultures (Fig. 3), overexpression of the full-length rPSD-95 in PSD-95 KO mouse slice cultures increased AMPAR EPSCs by approximately twofold (rPSD$95,-96.0 \pm 17.6 \mathrm{pA}$ vs control, $-38.1 \pm 5.0 \mathrm{pA}, n=10, p<0.05$; Fig. $4 C, D)$ and had no significant effect on NMDAR EPSCs (rPSD-95, $113.2 \pm 34.5 \mathrm{pA}$ vs control, $83.3 \pm 22.7 \mathrm{pA}, n=10$, $p=0.07)$. Thus, the effects of the reference constructs are consistent between rats and $\mathrm{KO}$ mice.

Then we overexpressed p95 $\Delta \mathrm{GK}$ in the PSD-95 KO background. It increased the peak amplitude of AMPAR EPSCs by more than twofold (p95 $\Delta \mathrm{GK},-120.5 \pm 22.5 \mathrm{pA}$ vs control, $-51.9 \pm 7.8 \mathrm{pA}, n=12, p<0.05$; Fig. $4 A, D)$, whereas the NMDAR EPSCs were not affected (p95 $\Delta \mathrm{GK}, 121.7 \pm 21.9 \mathrm{pA}$ vs control, $94.5 \pm 11.8 \mathrm{pA}, n=12, p=0.20$ ). Thus, the effects of p95 $\Delta$ GK appeared to be different between rat and PSD-95 KO mice. However, the effect of $\mathrm{p} 95 \Delta \mathrm{GK}$ was apparently bigger in the PSD-95 KO background. These results suggested that p95 $\Delta \mathrm{GK}$ could autonomously enhance AMPAR function, at least in PSD-95 KO mice. Moreover, any residual endogenous PSD-95 through the knockdown is unlikely to cause the partial effect of p95 $\Delta \mathrm{GK}$ in rat slice cultures.

We then examined the effect of PSD-95-to-p95 $\Delta$ GK replacement in WT mouse slice cultures to determine whether the discrepant results of $\mathrm{p} 95 \Delta \mathrm{GK}$ between rat and $\mathrm{KO}$ mouse slice cultures (Figs. 2, 4) were attributable to genetic manipulation (KO vs knockdown) or genetic background. Similar to rat slice cultures, knockdown of PSD-95 with sh95 reduced AMPAR EPSCs (sh95, $-63.2 \pm 9.5 \mathrm{pA}$ vs control, $-75.4 \pm 10.8 \mathrm{pA}, n=$ $24, p<0.05$; Fig. $5 A, C$ ) without significantly affecting NMDAR EPSCs (sh95, $47.3 \pm 7.5 \mathrm{pA}$ vs control, $-56.2 \pm 8.1 \mathrm{pA}, n=22$, $p=0.08)$. However, the AMPAR EPSC reduction in mouse slice cultures was significantly smaller than in rat slice culture [mouse: sh95/control, $0.84 \pm$ SEM $(+0.054 ;-0.049), n=24$; rat: sh95/ control, $0.51 \pm \operatorname{SEM}(+0.086 ;-0.078), n=38, p<0.01]$. PSD-95 is recruited into synapses during synapse maturation/ stabilization (Prange and Murphy, 2001; Yoshii et al., 2003; Ehrlich et al., 2007), whereas PSD-95-lacking synapses are structurally and functionally consistent with immature synapses (Béique et al., 2006). Thus, a potentially differential synaptic maturation pace could be one possible cause for the different amount $50 \mathrm{pA}, 25 \mathrm{~ms}$.
B

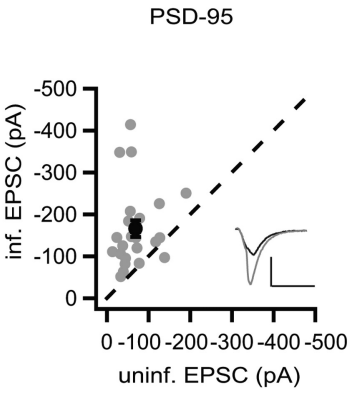

C

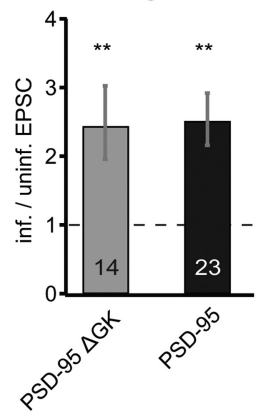

Figure 3. Expression of PSD-95 $\Delta$ GK enhanced AMPAR EPSCs in the presence of endogenous PSD-95. $A, B$, Amplitude peaks of 作 graph. Statistical significance is indicated with asterisks from the analysis in $\boldsymbol{A}$ and $\boldsymbol{B}$ to indicate difference from control. Calibration:

A
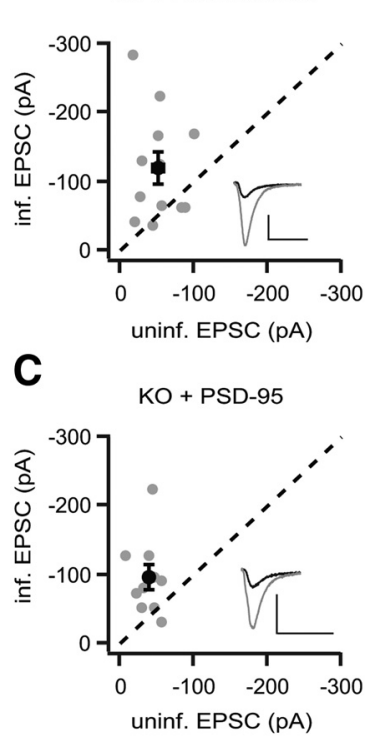

Figure 4. Expression of $\mathrm{p} 95 \Delta \mathrm{GK}$ enhanced AMPAR EPSCs in PSD-95 KO mice. $\boldsymbol{A}-\boldsymbol{C}$, Amplitude peaks of AMPAR EPSCs neurons expressing p95 $\mathrm{GK}(\boldsymbol{A}), \mathrm{PDZ1} / 2(\boldsymbol{B})$, or rPSD-95 (C) were plotted against those of simultaneously recorded uninfected neighboring neurons in PSD-95 K0 hippocampal slice cultures. D, Summary of AMPAR EPSC ratio of infected and uninfected pairs. Schematic representation of PSD-95 with color-coded domains, matching the bar colors and with diagonal stripes to indicate results from PSD-95 KO mice. Number of pairs $(n)$ indicated in the foot of the graph. Statistical significance is indicated with stars from the analysis in $\boldsymbol{A}-\boldsymbol{C}$ to indicate difference from control. Calibration: 50 pA, 25 ms.

of AMPAR EPSC reduction in rat and mouse slice culture by expression of sh95.

We then performed the PSD-95-to-p95 $\Delta$ GK replacement in WT mice. Similar to the overexpression of p95 $\Delta$ GK in PSD-95 KO mouse, the replacement increased the peak amplitudes of AMPAR EPSCs by $\sim 70 \%$ above the control WT cell levels (sh95 + p95 $\Delta \mathrm{GK},-72.5 \pm 9.2 \mathrm{pA}$ vs control, $-42.1 \pm 7.5 \mathrm{pA}, n=23, p<$ 0.01 ; Fig. $5 B, C)$, whereas NMDAR EPSCs were not changed $(\operatorname{sh} 95+$ p95 $\Delta$ GK, $34.4 \pm 5.6 \mathrm{pA}$ vs control, $30.6 \pm 4.4 \mathrm{pA}, n=$ 23, $p=0.27)$. Thus, p95 $\Delta$ GK enhanced AMPAR EPSCs both 
A sh95

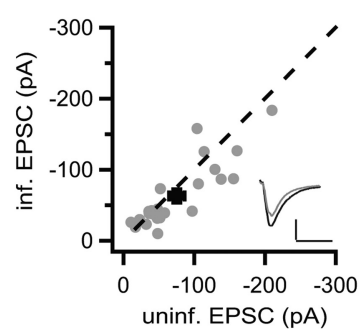

B

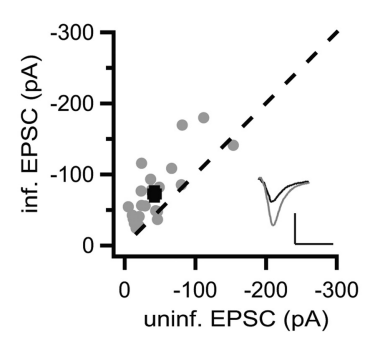

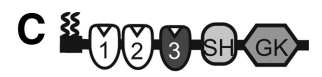

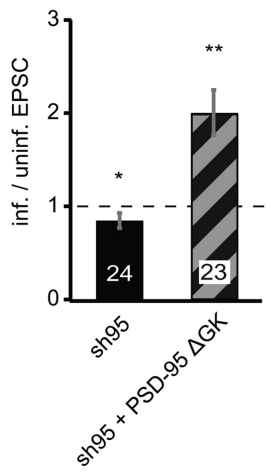

Figure 5. Expression of $p 95 \Delta G K$ enhanced AMPAR EPSCs when replacing endogenous PSD-95 in mouse slice cultures. $\boldsymbol{A}, \boldsymbol{B}$, Amplitude peaks of AMPAR EPSCs neurons expressing sh95 $(\boldsymbol{A})$ or sh95 + p95 $\mathrm{GK}(\boldsymbol{B})$ were plotted against those of simultaneously recorded uninfected neighboring neurons in mouse hippocampal slice cultures. C, Summary of AMPAR EPSC ratio of infected and uninfected pairs. Schematic representation of PSD-95 with color-coded domains, matching the bar colors. Number of pairs $(n)$ indicated in the foot of the graph. Statistical significance is indicated with asterisks from the analysis in $\boldsymbol{A}$ and $\boldsymbol{B}$ to indicate difference from control. Calibration: 50 pA, 25 ms.

when endogenous PSD-95 is knocked out in mice during the entire neuronal development and later in slice culture. Notably, overexpression of p95 $\Delta$ GK in PSD-95 KO mouse slice cultures caused a twofold increase in AMPAR EPSCs (Fig. 4), whereas the PSD-95-to-p95 $\Delta \mathrm{GK}$ in WT mouse slice cultures increased AMPAR EPSCs by 70\%. These seemingly discrepant results are not likely attributable to the different efficacies of the constructs or experimental approaches but to different comparison baselines. In PSD-95 KO mouse slices, the manipulated neurons were compared with their neighboring neurons that lacked PSD-95 and, as a consequence, with decreased AMPAR function compared with WT animals. In the PSD-95-top95 $\Delta$ GK replacement in WT mice, the manipulated neurons were compared with their neighboring WT neurons with likely normal AMPAR function (Fig. 5A).

In contrast, in rat slice cultures, PSD-95-to-p95 $\Delta$ GK replacement did only enhance AMPAR EPSCs to control WT neuron levels (Fig. 2C). Together, this set of results revealed that p95 $\Delta \mathrm{GK}$ increased the AMPAR function in both rats and mice but likely with a higher efficacy in mice.

\section{Loss of PSD-95 changed the protein level of postsynaptic paralogs and AMPAR subunits}

In an attempt to determine the mechanisms underlying the different efficacies of p $95 \Delta \mathrm{GK}$ between mouse and rat slice cultures, we examined and compared the responses of postsynaptic proteins in mouse and rat preparations during manipulations of PSD-95 and related DLG-MAGUKs.

We first examined the levels of DLG-MAGUKs in PSD-95 and PSD-93 KO mice (McGee et al., 2001b). We performed a subcellular fractionation procedure from the cortices of WT, PSD-93, and PSD-95 KO mice to isolate the PSD fraction (Cho et al., 1992). PSD marker proteins, such as PSD-93, PSD-95, and NMDAR subunits GluN2A and GluN2B, were present in the pellet fractions particularly enriched in the PSD fraction (TSP) (Fig. 6A). Soluble synaptic proteins (e.g., GDI) and synaptic vesicle proteins (e.g., Synaptophysin) were absent in the PSD fraction (Schlüter et al., 1999) (Fig. 6A). The cytoskeletal protein $\beta$-tubulin was distributed homogenously across all fractions. The AMPAR subunit GluA1 was enriched in the PSD fraction (Fig. 6A).
In PSD-93 and PSD-95 KO mice, PSD-93 and PSD-95 were absent, respectively, in the PSD fractions with no compensatory upregulation of one for the other in both $\mathrm{KO}$ mice (PSD-93: $F_{(2,7)}=$ 192.1, $p<0.01$; WT, $100 \pm 5.0$ vs PSD-95 $\mathrm{KO}, 100.8 \pm 3.2, p=0.99$; WT vs PSD-93 $\mathrm{KO}, 2.91 \pm 0.34, p<0.01$; PSD-95: $F_{(2,7)}=59.85, p<0.01 ; \mathrm{WT}, 100 \pm 7.2 \mathrm{vs}$ PSD-95 KO, $11.7 \pm 0.27, p<0.01$; WT vs PSD-93 KO, $105.6 \pm 8.0, p=0.82$; Fig. $6 B)$. Furthermore, the levels of two other DLG-MAGUKs, SAP97 and SAP102, were significantly increased in the PSD fraction of PSD-95 KO mice, but not in PSD-93 KO mice, compared with WT mice $\left(\right.$ SAP97: $F_{(2,11)}=21.43, p<0.01$; $\mathrm{WT}, 100 \pm 8.0$ vs p95 KO, $174.3 \pm 9.9$, $p<0.01$; WT vs $\mathrm{p} 93 \mathrm{KO}, 114.4 \pm 5.3, p=$ 0.56; SAP102: $F_{(2,7)}=17.50, p<0.01$; WT, $100 \pm 4.0$ vs PSD-95 KO, $187.6 \pm$ $16.4, p<0.01$; WT vs PSD-93 KO, $115 \pm$

$13.2, p=0.61$; Fig. $6 B$ ). These results were consistent with previous results, measuring changes of DLGMAGUKs in PSD-95 KO mice, in which an increase of SAP102 levels was also detected (Cuthbert et al., 2007). These results indicated that changes in one MAGUK (i.e., PSD-95) induced changes in another MAGUK with potentially similar synaptic functions.

We then examined the impact of PSD-95/93 on postsynaptic AMPARs and NMDARs. Our results thus far suggested that PSD-95 functions to upregulate AMPAR EPSCs. This result is consistent with the majority of related studies showing a decrease of AMPAR EPSCs when PSD-95 is knocked down or knocked out (Nakagawa et al., 2004; Béïque et al., 2006; Schlüter et al., 2006; Ehrlich et al., 2007; Carlisle et al., 2008) but at odds with others in which no changes of AMPAR EPSCs were detected in PSD-95 KO mice (Migaud et al., 1998; Elias et al., 2006). Measuring the protein levels of postsynaptic AMPARs would help determine how AMPARs are regulated by PSD-95/93 and help address the above discrepant results. As such, we quantified the AMPAR levels in the PSD fraction in PSD-95 and PSD-93 KO mice. The levels of AMPAR subunits GluA1 and GluA2 were decreased by $50 \%$ in PSD-95 KO, but not in PSD-93 KO, mice (GluAl: $F_{(2,7)}=13.25$, $p<0.01$; WT, $100 \pm 4.2$ vs PSD-95 KO, $45.5 \pm 1.9, p<0.01$; WT vs PSD-93 KO, 97.6 $\pm 11.7, p=0.70$; GluA2: $F_{(2,7)}=30.00, p<$ 0.01 ; WT, $100 \pm 4.3, n=4$ vs PSD-95 KO, $49.6 \pm 5.7, p<0.01$; WT vs PSD-93 KO, $91.9 \pm 4.8, p=0.49$; Fig. $6 B$ ). These results suggested that the numbers of AMPARs, not necessarily the function of AMPARs, was decreased during downregulation of PSD-95 in synapses. These results also supported the electrophysiological results showing a downregulation of AMPAR EPSCs during PSD-95 downregulation (Nakagawa et al., 2004; Béïque et al., 2006; Schlüter et al., 2006; Ehrlich et al., 2007; Carlisle et al., 2008).

Furthermore, the auxiliary AMPAR subunit Stargazin was also decreased in PSD-95 KO mice but not in PSD-93 KO mice (Stargazin: $F_{(2,7)}=15.56, p<0.01$; WT, $100 \pm 5.3$ vs PSD-95 KO, $59.6 \pm 4.3, p<0.01$; WT vs PSD-93 KO, $98.8 \pm 8.8, p=0.99$; Fig. $6 B)$. The levels of NMDAR subunits GluN1, GluN2A, and GluN2B were not changed significantly in either PSD-93 or PSD-95 KO mice (GluN1: $F_{(2,7)}=0.37, p=0.71$; WT, $100 \pm 5.3$; PSD-95 KO, $111.7 \pm$ 3.6; PSD-93 KO, 88.2 \pm 4.0; GluN2A: $F_{(2,7)}=0.12, p=0.89 ; \mathrm{WT}, 100 \pm 7.6$; PSD-95 KO, $105.1 \pm 9.0$; 
A

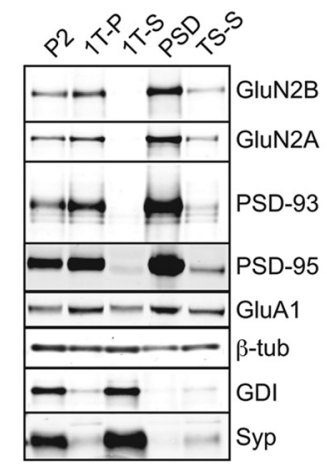

B
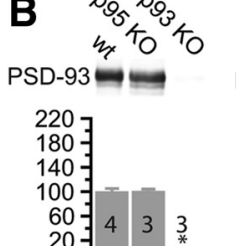

$20=4 \quad 3 \quad 3$

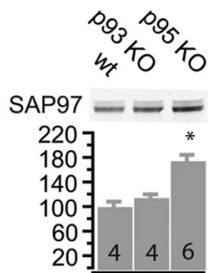

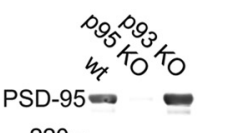
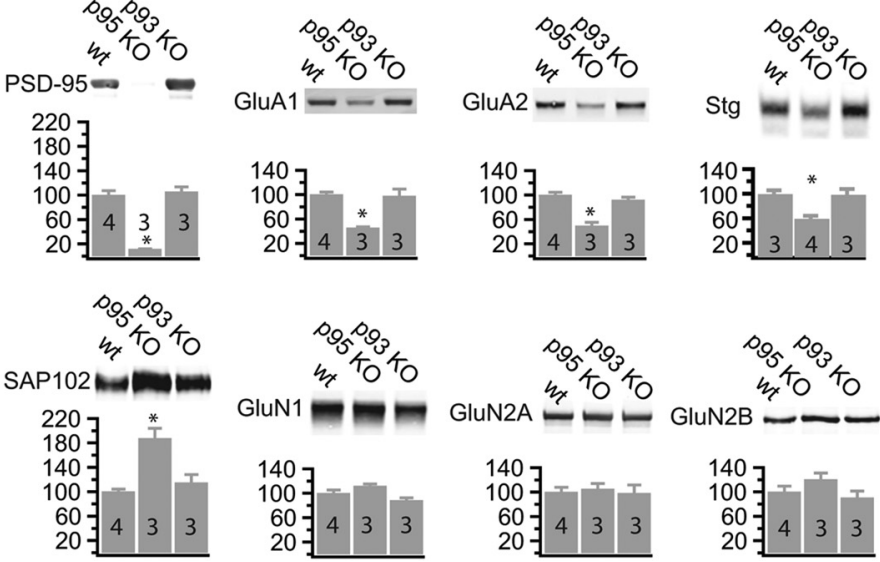

Figure 6. Compensatory increases of DLG-MAGUK levels in the PSD of PSD-95 K0 mice. Subcellular fractionations with differential centrifugation and detergent extractions were performed of single cortices of control, PSD-93 K0, and PSD-95 K0 mice. Thirty micrograms of total protein were processed by SDS-PAGE and immunoblotted with antibodies directed against the indicated proteins ( $\beta$-tub, $\beta$-tubulin; Syp, Synaptophysin). A, Characterization of different fractions [P2, crude synaptosomes; 1T-P, Triton X-100 extraction pellet; 1 T-S, Triton X-100 extraction supernatant; PSD, postsynaptic density ( $N$-lauroyl-sarcosyl extraction pellet); TS-S, N-lauroyl-sarcosyl supernatant]. $\boldsymbol{B}$, Sample immunoblot of the indicated proteins is illustrated on the top, and quantified protein amounts (mean \pm SEM) normalized against the mean of control animals on each blot is plotted against the genotype. Number of animals ( $n$ ) indicated as number in the foot of the bar. Statistical significance is indicated with asterisks, tested with ANOVA and post hoc analysis of test sample versus control.

PSD-93 KO, $98.26 \pm 13.4 ;$ GluN2B: $F_{(2,7)}$ $=2.03, p=0.20$; WT, $100 \pm 9.4$; PSD-95 KO, $120.5 \pm 10.5$; PSD-93 KO, $90.4 \pm$ 11.0; Fig. $6 B$ ), consistent with our above and previous electrophysiological results showing lack or minimal changes in NMDAR EPSCs during PSD-95 knockdown (Elias et al., 2006; Schlüter et al., 2006). Collectively, these results suggested that a loss of PSD-95 decreases the number of AMPARs in the PSD, which mediates the decreased amplitude of AMPARmediated basal synaptic transmission in PSD-95 KO mice.

After confirming the basic function of PSD-95 and PSD-93 using KO mice, we next attempted to delineate the potentially differential effects of these MAGUKs between rats and mice. We used cortical neuronal cultures to get sufficient number of neurons for the subcellular fractionation procedure (Ehlers, 2003). In PSD-95 KO mice, PSD-95 was absent during the entire neuronal development, whereas in our shRNA experiments, the PSD-95 levels were decreased after an animal age of 8 d. To examine the effect of PSD-95 knockdown at different developmental stages, we reduced the PSD-95 levels at three different time points (DIV0, DIV7, and DIV12), approximating time points before, during, and at a later stage of synaptogenesis. We used a subcellular fractionation procedure to isolate the Triton X-100-insoluble fraction from the cultures. Both GluN2B and PSD-95 were enriched from homogenate $(\mathrm{H})$ over the crude synaptosomal fraction (P2) to the Triton $\mathrm{X}-100$ pellet fraction (1TP) (Fig. 7A). The soluble presynaptic protein GDI and synaptic vesicle-associated protein Rab3A were depleted in this fraction (Fig. 7A). PSD-95 was efficiently downregulated with the sh95s in both mouse and rat cultures at all three transduction time points (Fig. $7 B, C$ ). The level of GluN2B
B
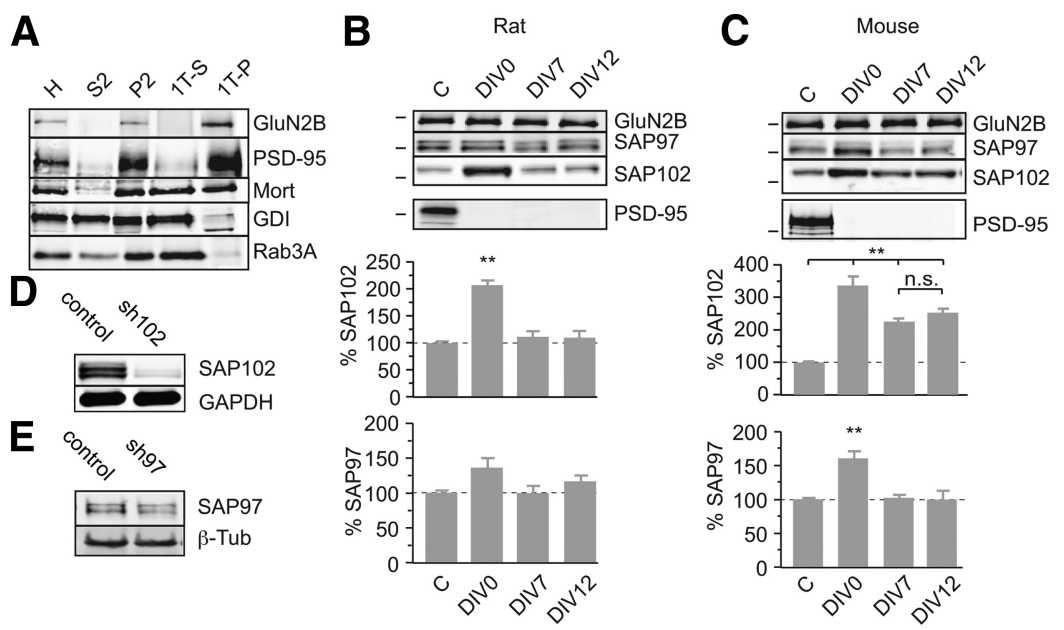

Figure 7. Compensatory increases of DLG-MAGUKs levels in the Triton X-100-insoluble fraction of dissociated neuronal cultures. Subcellular fractionations with differential centrifugation and detergent extractions were performed on dissociated mouse or rat cortical cultures after DIV21, transduced at different time points with sh95 (C, GFP expression control; D0, transduction at DIV0; D7, transduction at DIV7; D12, transduction at DIV12). Ten micrograms of total protein were processed by SDS-PAGE and immunoblotted with antibodies directed against the indicated proteins (Mort, mortalin). $A$, Characterization of different fractions (H, homogenate; S2, cytosolic and microsomal fraction; P2, crude synaptosomes; 1T-P, Triton X-100 extraction pellet; 1T-S, Triton X-100 extraction supernatant). $\boldsymbol{B}, \boldsymbol{C}$, Sample immunoblots of the 1T-P fraction (top three) and P2 fraction (PSD-95) of indicated proteins is illustrated on the top and quantified protein amounts (mean \pm SEM) normalized against the mean of control condition on each blot is plotted against the experimental condition $[n=6 \mathrm{rat}(\boldsymbol{B})$ or mouse $(\boldsymbol{C})$ cultures]. Statistical significance is indicated with asterisks, tested with ANOVA and post hoc analysis of experimental condition versus control or when indicated with bar among all indicated conditions. D, E, Sample immunoblots of mouse hippocampal cultures transduced with sh102 (D), sh97 (E), or control lentiviral vector, probed with indicated antibodies.

as an operational indicator for the overall protein level of PSDs was not different among all culture conditions (GluN2B mouse: $F_{(3,8)}=0.65, p=0.61$; control, $100 \pm 0.06 \%, n=3$; DIV0, $111 \pm$ $0.04 \%, n=3$; DIV7, $105 \pm 0.08 \%, n=3$; DIV12, $108 \pm 0.07 \%$, $n=3$; GluN2B rat: $F_{(3,8)}=0.81, p=0.52$; control, $100 \pm 0.01 \%$, $n=3$; DIV0, $102 \pm 0.04 \%, n=3$; DIV7, $95.2 \pm 0.03 \%, n=3$; DIV12, $98.2 \pm 0.03 \%, n=3$; Fig. $7 A-C$ ). Similar to that in PSD fractions in PSD-95 KO mice, the level of GluN2B did not change in the 1TP fractions in both rat and mouse cultures during PSD-95 knockdown. In rat neuronal cultures, the level of SAP102 was increased (approximately twofold) on DIV0, but not DIV7 or 
A

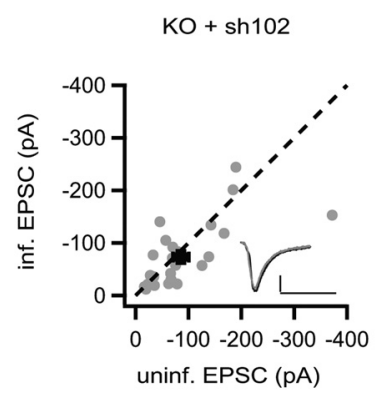

B

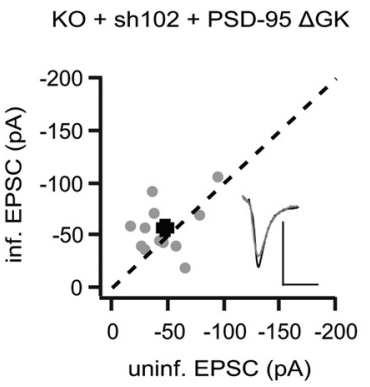

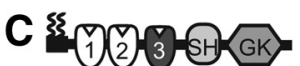

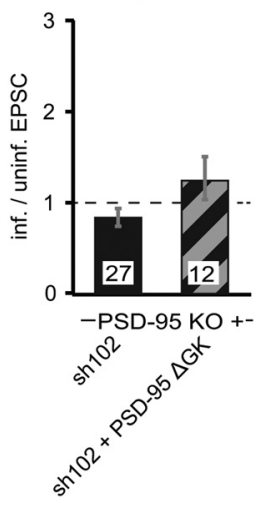

Figure 8. p95 $\triangle$ GK-mediated enhancement of AMPAR EPSCs in PSD-95 K0 mice was dependent on increased SAP102 levels. $\boldsymbol{A}$, $\boldsymbol{B}$, Amplitude peaks of AMPAR EPSCs of neurons expressing sh102 $(\boldsymbol{A})$ or sh102 $+p 95 \Delta G K(\boldsymbol{B})$ are plotted against those of simultaneously recorded uninfected neighboring neurons in PSD-95 KO hippocampal slice cultures. C, Summary of AMPAR EPSC ratio of infected and uninfected pairs. Schematic representation of PSD-95 with color-coded domains, matching the bar colors. Number of pairs $(n)$ indicated in the foot of the graph. Calibration: 50 pA, 25 ms.

DIV12, PSD-95 knockdown (SAP102, control, $100 \pm 2.2 \%$; DIV0, $208 \pm 8.6 \%$; DIV7, $112 \pm 9.8 \%$; DIV $12,110 \pm 13.8 \%$; $F_{(3,20)}=28.04, p<0.01 ; p<0.01$, DIV0 vs other conditions; Fig. $7 B)$. The levels of SAP97 were not significantly changed during PSD-95 knockdown at each time point but with a trend toward an increase for the DIV0 transduction (SAP97, control, $100 \pm$ 3.9\%; DIV0, $136 \pm$ 14.2\%; DIV7, $98.8 \pm 11.2 \%$; DIV12, $116 \pm$ $9.3 \% ; F_{(3,20)}=2.79, p=0.07$; Fig. $7 B$ ). In mouse neuronal cultures, knockdown of PSD-95 increased the level of SAP102 at all three time points (SAP102, control, $100 \pm 3.3 \%$; DIV0, $337 \pm$ $39.0 \%$; DIV7, $226 \pm 9.1 \%$; DIV12, $253 \pm 11.7 \%$; $F_{(3,20)}=22.08$, $p<0.01 ; p<0.01$, DIV0 vs any other condition; Fig. $7 C)$. The levels of SAP97 increased when PSD-95 was knocked down at DIV0 but not at other time points (SAP97: $F_{(3,20)}=19.83, p<$ 0.01 ; control, $100 \pm 2.6 \%$ vs DIV0, $160 \pm 11.3 \%, p<0.01$; control vs DIV7, $102 \pm 5.4 \%, p=0.99$; control vs DIV12, $99.2 \pm$ $4.3 \%, p=0.99$; Fig. $7 C$ ). These results suggested that, at DIV0, when the synaptogenesis process has not been fully activated, PSD-95 knockdown increased the protein levels of SAP102, also possibly SAP97. However, the effects of PSD-95 knockdown differed in mice and rats at later time points. As such, in the PSD95-to-p95 $\Delta$ GK experiment, knockdown of PSD-95 in relatively developed rat organotypic slices should not change the level of SAP102. In contrast, in the PSD-95-to 950 GK experiment using mouse slices, the level of SAP102 is expected to be elevated; indeed, the levels of SAP102 were higher in PSD-95 KO mice (Fig. 6). We hypothesize that the differential effects of PSD-95 downregulation on SAP102 in mice and rats mediate the differential effects of the PSD-95-to-p95 $\Delta$ GK replacement on AMPAR EP$\mathrm{SCs}$ in these two species. Additionally, these results suggested that the development of synapses in our mouse neuronal cultures was attenuated, a conclusion that is consistent with the reduced efficiency of AMPAR EPSC reduction in mouse slice cultures with sh95 (Fig. 5).

\section{Functional interaction between SAP102 and p95 $\Delta$ GK enhanced AMPAR EPSCs}

DLG-MAGUKs interact with each other intramolecularly and intermolecularly by their SH3 and GK domains (McGee et al., 2001a). We tested whether the increased SAP102 levels were responsible for the enhancing effect of p $95 \Delta$ GK on AMPAR EPSCs.

We developed an shRNA targeting SAP102 (sh102), which knocked down SAP102 by $\sim 90 \%$ (Fig. $7 D$ ). We then expressed sh102 to knockdown SAP102 in slice cultures from PSD-95 KO mice, in which the level of SAP102 would be otherwise much higher compared with WT controls (Fig. 6). Both AMPAR and NMDAR EPSCs in sh102-expressing neurons were not significantly different from those in control neurons (sh102 AMPAR, $-85.7 \pm 14.7 \mathrm{pA}$ vs control, $-73.3 \pm 11.5$ $\mathrm{pA}, n=27, p=0.25 ; \mathrm{NMDAR}, 66.8 \pm 9.6$ pA vs control, $62.0 \pm 7.9 \mathrm{pA}, n=27, p=$ 0.19 ; Fig. $8 A, C)$. These results suggested that reducing SAP102 in the absence of PSD-95 did not affect AMPARs.

We then expressed the sh102 together with $\mathrm{p} 95 \Delta \mathrm{GK}$ in PSD-95 KO mouse slice cultures. This manipulation did not significantly affect AMPAR EPSCs but increased the peak amplitudes of NMDAR EPSCs (sh102 + p95 $\Delta$ GK AMPAR, $-56.8 \pm 7.1$ pA vs control, $-46.6 \pm 6.7 \mathrm{pA}, n=12, p=0.22$; NMDAR, $57.7 \pm 9.1 \mathrm{pA}$ vs control, $41.6 \pm 5.8 \mathrm{pA}, n=12, p<0.05$; Fig. $8 A, C)$. In contrast, the PSD-95-to-p95 $\Delta$ GK replacement increased AMPAR EPSCs by approximately twofold in PSD-95 KO mice, in which the level of SAP102 was high (Figs. 4, 6). These results together suggested that the presence of SAP102 is essential for p95 $\Delta$ GK to enhance AMPAR EPSCs. As such, we conclude that the GK domain is required for PSD-95 to enhance AMPAR EPSCs autonomously, but this requirement can be "shortcut" by upregulation of SAP102, likely through a functional interplay between PSD-95 and SAP102.

Because the level of SAP97 was also increased in the PSD-95 KO, we tested whether, similar to SAP102, the increased SAP97 could also restore the full functionality of p $95 \Delta \mathrm{GK}$ in the $\mathrm{KO}$ mice. We generated an shRNA against SAP97 (sh97), which exhibited a knockdown efficacy of $\sim 40 \%$ (Fig. $7 E$ ). We expressed this shRNA together with p95 $\Delta \mathrm{GK}$ in hippocampal slice cultures from PSD-95 KO mice. Downregulation of SAP97 did not prevent the enhancing effect of p95 $\Delta \mathrm{GK}(\mathrm{sh} 97+\mathrm{p} 95 \Delta \mathrm{GK},-123.9 \pm 13.5 \mathrm{pA}$ vs control, $-87.7 \pm 10.5 \mathrm{pA}, n=23, p<0.01)$, and this manipulation did not affect NMDAR EPSCs (sh97 + p95 $\Delta$ GK, $63.6 \pm 6.6 \mathrm{pA}$ vs control, $68.4 \pm 8.3 \mathrm{pA}, n=23, p=0.65)$. Thus, SAP97 did not possess the capacity to restore the full PSD-95 function for p95 $\Delta \mathrm{GK}$.

\section{The SH3 of PSD-95 mediated the functional interplay between SAP102 and PSD-95 mutants}

To gain insight into the mechanism underlying the functional interplay between SAP102 and PSD-95 mutants, we extended our analysis with the other deletion constructs p95 $\mathrm{PDZ} 3$ and p95 $\Delta$ SH3. p95 $\Delta$ PDZ3 enhanced AMPAR EPSCs in PSD-95 KO mouse slice cultures (p95 $\mathrm{PDZ} 3,-102.9 \pm 18.3 \mathrm{pA}$ vs control, $-78.4 \pm 12.3$ pA, $n=21, p<0.05$; Fig. $9 A, E$ ) without affecting NMDAR EPSCs (p95 $D$ PDZ3, $54.6 \pm 9.9$ pA vs control, $60.1 \pm$ $12.0 \mathrm{pA}, n=21, p=0.37$ ). Furthermore, knocking down SAP102 by coexpression of sh102 prevented the enhancing effect of p95 $\triangle$ PDZ3 on AMPAR EPSCs (sh102 + p95 PPDZ3, $-81.0 \pm 14.9$ pA vs control, $-83.8 \pm 18.4 \mathrm{pA}, n=24, p=0.20$; Fig. $9 B, E)$, and this manipulation did not affect NMDAR EPSCs (sh102+ p95 $\Delta$ PDZ3, $47.4 \pm 7.5 \mathrm{pA}$ vs control, $55.6 \pm 12.1 \mathrm{pA}, n=22, p=$ 
0.21). Thus, similar to p95 $\Delta \mathrm{GK}$, the AMPAR-enhancing effect of p95 PDZ3 could also be restored by SAP102 upregulation.

The SH3 was not essential for PSD-95 to enhance AMPARs (Fig. 2). Similar to the effect in rat slice cultures, expression of p $95 \Delta \mathrm{SH} 3$ in PSD-95 KO mouse slice cultures enhanced AMPAR EPSCs by approximately twofold (p95 $\Delta \mathrm{SH} 3,-138.0 \pm 20.1 \mathrm{pA}$ vs control, $-60.7 \pm 7.2$ pA, $n=11, p<0.01$; Fig. $9 C, E$ ) without affecting NMDAR EPSCs (p95 $\Delta$ SH3, $130.0 \pm 21.5$ pA vs control, $114.0 \pm$ $21.7 \mathrm{pA}, n=11, p=0.37$ ). The AMPAR-enhancing effect of p95 $\triangle \mathrm{SH} 3$ was not prevented by simultaneous knockdown of SAP102 or SAP97 with coexpression of sh102 $(\operatorname{sh} 102+$ p95 $\Delta$ SH3, $-106.3 \pm 16.3 \mathrm{pA}$ vs control, $-48.3 \pm 9.2 \mathrm{pA}, n=10, p<0.01$; Fig. $9 D, E)$ or sh97 $(\operatorname{sh} 97+\mathrm{p} 95 \Delta \mathrm{SH} 3,-136.7 \pm 20.4 \mathrm{pA}$ vs control, $-37.8 \pm 5.7 \mathrm{pA}, n=18, p<0.01)$. These manipulations did not affect NMDAR EPSCs (sh102 + p95 $\Delta$ SH3, $84.7 \pm 19.8$ pA vs control, $75.7 \pm 17.2 \mathrm{pA}, n=10, p=0.37$; sh97 $+\mathrm{p} 95 \Delta \mathrm{SH} 3,43.2 \pm 8.5$ $\mathrm{pA}$ vs control, $34.4 \pm 4.8 \mathrm{pA}, n=18, p=0.15)$. These results confirmed that the SH3 domain was not required for the PSD-95mediated enhancement of AMPAR EPSCs, and the levels of SAP102 or SAP97 did not affect the function of PSD-95 constructs lacking the $\mathrm{SH} 3$ domain.

p95 $\Delta \mathrm{GK}$ and p95 $\mathrm{PDZ3}$ enhanced AMPARs through a functional interplay with elevated SAP102 in PSD-95 KO slice cultures (Figs. 8, 9). Both constructs have three common domains: the first two PDZ domains and the $\mathrm{SH} 3$ domain. The first two PDZ domains are essential for synaptic targeting and enhancement in the presence of endogenous PSD-95 and thus cannot be deleted for testing the functional interaction with SAP102 (Craven et al., 1999; Schnell et al., 2002). To test whether the SH3 domain mediated the functional interplay, we generated a "minimal" construct, consisting of only the $\mathrm{PDZ} 1 / 2$ domain fused to the SH3 domain (PDZ1/2-SH3). Expression of this construct in PSD-95 KO mouse slice cultures enhanced the peak amplitudes of AMPAR EPSCs by approximately twofold (PDZ1/2-SH3, $-120.5 \pm 17.3 \mathrm{pA}$ vs control, $-62.2 \pm 7.5$ pA, $n=18, p<0.01$; Fig. $10 A, C)$ and NMDAR EPSCs by $\sim 25 \%$ (PDZ1/2-SH3, $112.6 \pm 22.2 \mathrm{pA}$ vs control, $86.9 \pm 20 \mathrm{pA}, n=17, p<0.01)$. Furthermore, the AMPAR- and NMDAR-enhancing effect of this minimal PSD-95 was prevented by coexpression of sh102 (AMPAR EPSC, sh102 + $\mathrm{PDZ1} / 2-\mathrm{SH} 3,-93.6 \pm 18.0 \mathrm{pA}$ vs control, $70.5 \pm 10.6 \mathrm{pA}, n=18$, $p=0.17$; NMDAR EPSC, sh102 + PDZ1/2-SH3, $61.4 \pm 9.4 \mathrm{pA}$ vs control, $57.3 \pm 12.9 \mathrm{pA}, n=18, p=0.67$; Fig. $10 B, C)$. Thus, the functional loss by deleting both PDZ3 and GK could be overcome by an interplay of SAP102 with the SH3 domain of the PSD-95 mutant. To clarify whether it is mediated through a direct intermolecular interaction with the SAP102 GK domain or indirectly through associations of the DLG-MAGUKs to the same multimeric receptor complexes will need additional experimentation (Masuko et al., 1999; McGee et al., 2001a). In conclusion, our results showed that the $\mathrm{SH} 3$ domain is dispensable in PSD-95 for enhancing AMPARs and that the function of the PDZ3 and GK domains can be compensated through a functional interplay with SAP102.

\section{Discussion}

Postsynaptic clustering of PSD-95 requires N-terminal multimerization and the first two PDZ domains (Craven et al., 1999; Xu et al., 2008). A construct consisting of these domains, PDZ1/2, is considered as the minimal PSD-95, because overexpression of it enhances AMPAR EPSCs, similar to full-length PSD-95 (Schnell et al., 2002). However, this construct relies on the interaction with endogenous PSD-95 to form a complex to function (Xu et al., 2008). Here, we identified additional requirements for
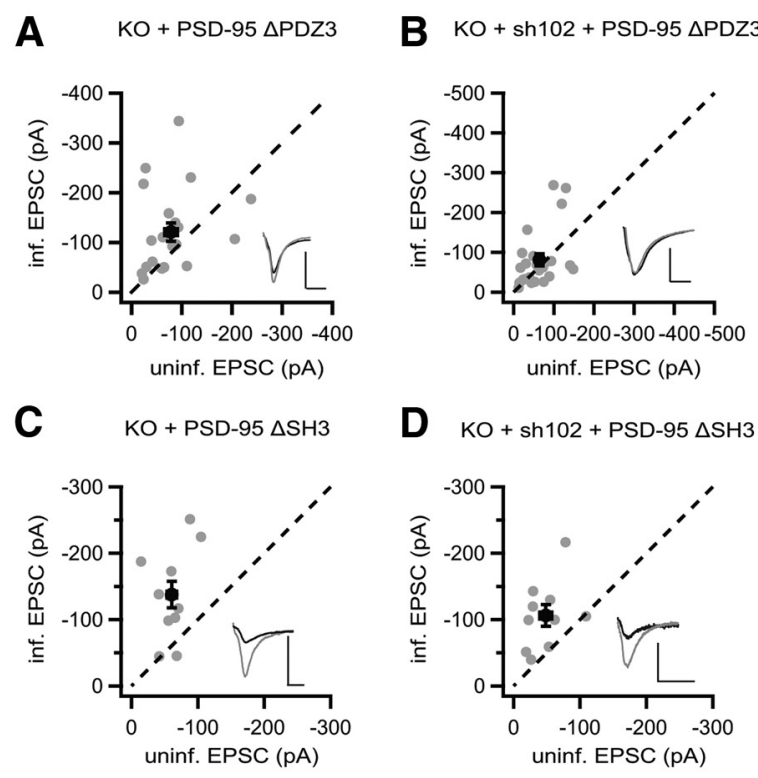

D $\mathrm{KO}+\operatorname{sh} 102+\mathrm{PSD}-95 \Delta \mathrm{SH} 3$
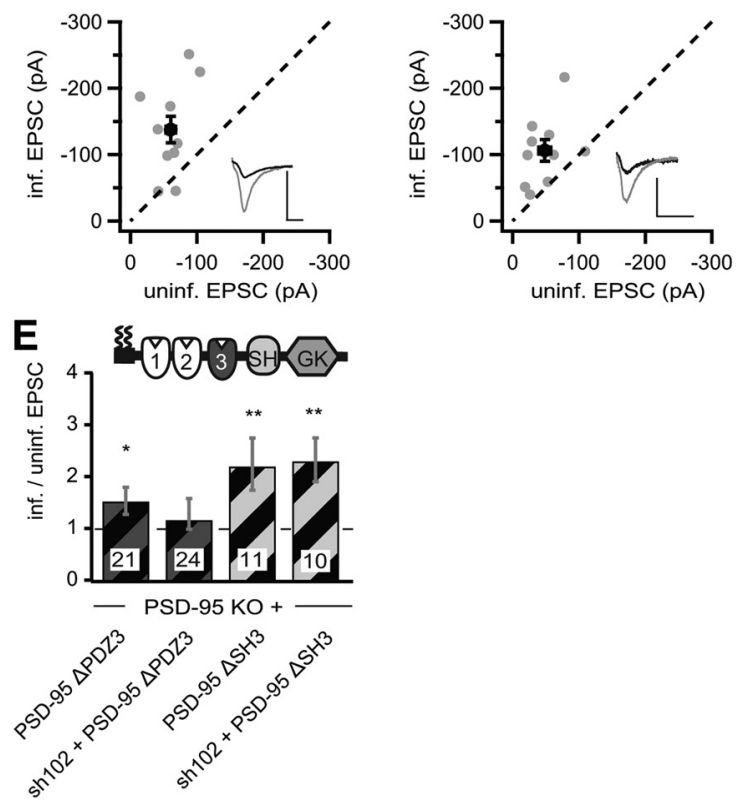

Figure 9. p95 $\triangle$ PDZ3-mediated enhancement of AMPAR EPSCs in PSD-95 K0 mice was dependent on increased SAP102 levels. $\boldsymbol{A}-\boldsymbol{D}$, Amplitude peaks of AMPAR EPSCS neurons expressing p95 $\Delta$ PDZ3 $(\boldsymbol{A}), \operatorname{sh} 102+$ p95 $\Delta$ PDZ3 $(\boldsymbol{B})$, p95 $\Delta$ SH3 $(\boldsymbol{C})$, or sh102 + p95 $\Delta$ SH3 $(\boldsymbol{D})$ were plotted against those of simultaneously recorded uninfected neighboring neurons in PSD-95 KO hippocampal slice cultures. $\boldsymbol{E}$, Summary of AMPAR EPSC ratio of infected and uninfected pairs. Schematic representation of PSD-95 with color-coded domains, matching the bar colors. Number of pairs $(n)$ indicated in the foot of the graph. Statistical significance is indicated with asterisks from the analysis in $\boldsymbol{A}-\boldsymbol{D}$ to indicate difference from control. Calibration: $50 \mathrm{pA}, 25 \mathrm{~ms}$.

PSD-95 to autonomously enhance AMPAR EPSCs. We show that only the SH3 domain was dispensable for the function of PSD-95 to enhance basal synaptic transmission (Fig. 2). Furthermore, both the PDZ3 and GK domains played permissive roles in regulating AMPAR function. In rat slice cultures in which the synapses were relatively mature, deletion of either of these domains attenuated the PSD-95-mediated enhancement of AMPAR function. However, different from PDZ1/2, which had no autonomous PSD-95 function, both PSD-95-to-p95 PDZ3 and PSD95-to-p95 $\Delta$ GK molecular replacements rescued AMPAR EPSCs to control WT cell levels. In slice cultures in which synapses are relatively immature, both constructs were fully functional in enhancing AMPAR EPSCs (Figs. 4, 8). Differences in the protein levels of SAP102 mediated this synaptic maturation statedependent function of PSD-95 mutants. Loss of PSD-95 in immature synaptic states caused a compensatory upregulation of SAP102, whereas in mature synapses, the SAP102 levels remained stable. A functional interplay between the PSD-95 mutant constructs and elevated SAP102 recovered their full potency to enhance AMPARs (Figs. 8, 9). This interaction was mediated 
A

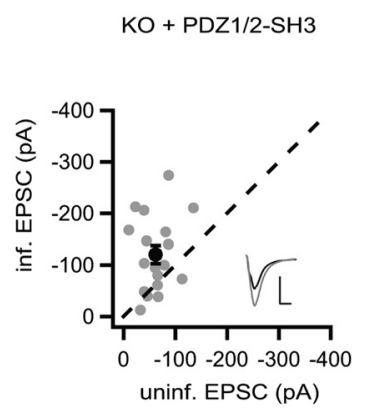

B

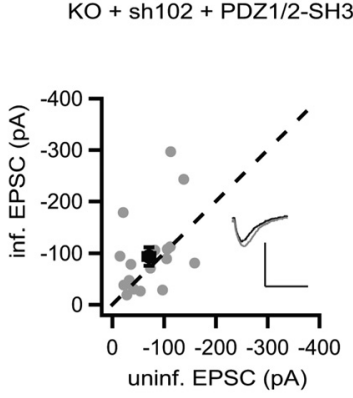

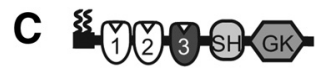

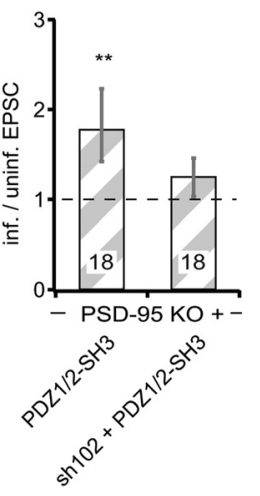

Figure 10. A minimal PSD-95 was dependent on the functional interaction with SAP102. $A, B$, Amplitude of AMPAR EPSCS of neurons expressing PDZ1/2-SH3 $(\boldsymbol{A})$ or sh102 + PDZ1/2-SH3 $(\boldsymbol{B})$ were plotted against those of simultaneously recorded uninfected neighboring neurons in PSD-95 KO hippocampal slice cultures. C, Summary of AMPAR EPSC ratio of infected and uninfected pairs. Schematic representation of PSD-95 with color-coded domains, matching the bar colors. Number of pairs $(n)$ indicated in the foot of the graph. Statistical significance is indicated with asterisks from the analysis in $\boldsymbol{A}$ and $\boldsymbol{B}$ to indicate difference from control. Calibration: $50 \mathrm{pA}, 25 \mathrm{~ms}$.

through the SH3 domain of PSD-95 mutants and untangled a functional link between different DLG-MAGUK family members (Fig. 10).

\section{Structural requirements of a minimal PSD-95 for enhancing AMPAR EPSCs autonomously}

Our results demonstrate that, in addition to the N-terminal multimerization domain and the AMPAR binding PDZ1/2 domains, the PDZ3 and GK domains were required for PSD-95 to autonomously enhance AMPAR function (Xu et al., 2008; Fig. 2). The $\mathrm{N}$-terminal domain of PSD-95 is characterized by two palmitoylated cysteines and a highly conserved motif as part of a PEST (for proline, glutamic acid, serine, and threonine) sequence (Colledge et al., 2003). Both the palmitoylation and the PEST motif are required for the multimerization of PSD-95, which is essential for the synaptic targeting and the function of enhancing AMPAR EPSCs (Schnell et al., 2002; Xu et al., 2008). This N-terminal multimerization also allows the assembly of WT PSD-95 with recombinantly expressed mutant PSD-95. With this multimerization, overexpression of a mutant PSD-95 containing only two PDZ domains is sufficient to enhance AMPAR EPSCs. Notably, deletion of either of first two PDZ domains impairs synaptic targeting and synaptic function of PSD-95 mutants (Craven et al., 1999; Schnell et al., 2002). The first two PDZ domains differ from the third PDZ domain in its topology and interaction partners. The first two PDZ domains bind preferentially to transmembrane receptors and ion channels (Kim et al., 1995; Kornau et al., 1995; Garcia et al., 1998; Schnell et al., 2002), whereas the third PDZ domain binds to intracellular ligands, such as cysteinerich interactor of PDZ three, and cell adhesion molecules, such as neuroligins (Irie et al., 1997; Niethammer et al., 1998). The first two PDZ domains are connected by a short linker and are oriented in parallel (Long et al., 2003). This arrangement is suitable for them to bind ligands from multimeric proteins synergistically, such as receptor clusters. The third PDZ domain connects to the first two through a linker, which is of variable length among different DLG-MAGUK family members. Our data suggest that the recruitment of one or multiple of these intracellular ligands and/or cell adhesion molecules is essential for the autonomous regulatory function of PSD-95 in basal synaptic transmission.

The GK domain binds to GKAP/ synapse-associated protein-associated protein, a hypothesized master regulator of synaptic strength (Kim et al., 1997; Takeuchi et al., 1997; Ehlers, 2003). PSD-95, GKAP, and Shank are postulated to form the core structure of the PSD (Valtschanoff and Weinberg, 2001; Hayashi et al., 2009). The protein amount estimations predicted that there are up to equimolar levels of these three protein families in the synapse (Peng et al., 2004; Kuriu et al., 2006). The functional link among these three proteins is further suggested by the finding that the PSD-95 and GKAP levels are positively correlated. In dendritic spines, the GKAP levels increase in parallel with the increase of PSD-95 (El-Husseini et al., 2000). However, when PSD-95 $\Delta \mathrm{GK}$ is overexpressed, the GKAP levels do not change, suggesting that the GK domain is the key site for PSD-95 to interact with GKAP. It appears that the level of GKAP does not directly affect AMPARs, because PSD-95 $\Delta$ GK overexpression increases AMPAR EPSCs despite the lack of change in GKAP. Thus, although the interaction between the PSD-95 multimer and GKAP is essential for the regulation of basal synaptic transmission, the number of GKAP molecules per se is not critical.

\section{Synaptic state-dependent requirements for minimal PSD-95 constructs}

We found differences between the enhancing effects of PSD$95 \Delta G K$ and PSD-95 PDZ3 in rat slice cultures and slice cultures from PSD-95 KO mice (Figs. 2, 4, 9). A critical technical difference in the rat and mouse experiments was that, in the KO mice, synapses developed in the absence of PSD-95, whereas in rat slice cultures, PSD-95 was abolished later by the replacement manipulation. Thus, the different effects of the two constructs between rats and mice may be a consequence of PSD-95-mediated developmental regulation of synaptic proteins. Consistent with this notion, the synaptic composition was different when PSD-95 was reduced at different developmental time points. The levels of synaptic SAP102 were increased in rat neuronal cultures only, when PSD-95 was knocked down before, but not after, the onset of synaptogenesis (on DIV0; Fig. 7). We speculate that the early knockdown of PSD-95 maintains the newly generated synapses in the immature state, similar to the synapses in PSD-95 KO mice (Béique et al., 2006). Without PSD-95, the synaptic SAP102 levels continue to increase. This may partially explain the high level of SAP102 in PSD-95 KO mice (Fig. 6). However, there is a glaring difference in PSD-95-mediated regulation of SAP102 between rats and mice. Unlike rat neuronal cultures, in mouse neuronal cultures, the increase of SAP102 was independent of the time point of PSD-95 knockdown. This difference explains the differential synaptic effects of the same PSD-95 mutants in mouse and rat slice cultures. The mechanisms underlying the species-based differences are not clear, but one possibility is that neurons from mice and rats may respond differently to the culture conditions, resulting in different synaptic properties. The culture conditions are influential; under a culture condition different from ours, PSD-95-to-PSD-95 $\Delta$ GK replacement is able to autonomously enhance AMPAR function in rat slices (Jo et al., 2010), a result opposite to our finding. We speculate that, under their condi- 
tions, SAP102 levels are elevated to mediate the enhancing effect of PSD-95 GK. These results suggest that the onset of expression of PSD-95 is critical for PSD-95-mediated regulation of synaptic SAP102 and thus the function of AMPARs (Sans et al., 2000; Yoshii et al., 2003).

\section{Functional interaction between SAP102 and PSD-95 to enhance AMPAR EPSCs}

Overexpression of PSD-95 GK and PDZ1/2-SH3 enhanced AMPAR function in PSD-95 KO mice (Figs. 4, 10). This enhancement was dependent on elevated SAP102 levels, because knockdown of SAP102 prevented the enhancement. In addition, in rat cultures in which the SAP102 levels were not elevated (Fig. 7), PSD-95-to-PSD-95 GGK replacement did not produce the enhancing effect on AMPAR EPSCs (Fig. 2). These results indicated a molecular interplay between PSD-95 mutants and endogenous SAP102. We speculate that the SH3 domain of PSD-95 and the GK domain of SAP102 interact directly, because in heterologous expression systems, DLG-MAGUKs cluster through additional C-terminal interactions (Masuko et al., 1999; McGee et al., 2001a). However, both DLG-MAGUKs can also be linked through receptor complexes, which are tetrameric and can bind to different DLG-MAGUKs through transmembrane AMPARassociated proteins (Dakoji et al., 2003). Our results also show that the elevated SAP102 alone was not able to enhance AMPAR EPSCs, but interaction of SAP102 with PSD-95 was. Conversely, SAP102 can substitute for missing domains of PSD-95, potentially by mediating the essential interactions with intracellular signaling molecules, the PSD matrix, or cell adhesion molecules. Notably, the presence of at least one of these signaling scaffolds is essential for synaptic function, because the double KO of PSD-95 and SAP102 is lethal (Cuthbert et al., 2007).

In conclusion, we identified the essential domains (minimal PSD-95) for PSD-95 to regulate synaptic AMPARs under different conditions. We also identified the development-dependent requirements of the different PSD-95 domains and a potential molecular interplay between PSD-95 and SAP102. These results highlight the importance of molecular crosstalks and the need for additional assessment of the development-dependent synaptic regulation. These results pave the path to understand the roles of MAGUKs and their interactions in basal synaptic transmission and long-term synaptic plasticity.

\section{References}

Abegg MH, Savic N, Ehrengruber MU, McKinney RA, Gähwiler BH (2004) Epileptiform activity in rat hippocampus strengthens excitatory synapses. J Physiol 554:439-448. CrossRef Medline

Balch WE, Rothman JE (1985) Characterization of protein transport between successive compartments of the Golgi apparatus: asymmetric properties of donor and acceptor activities in a cell-free system. Arch Biochem Biophys 240:413-425. CrossRef Medline

Béique JC, Andrade R (2003) PSD-95 regulates synaptic transmission and plasticity in rat cerebral cortex. J Physiol 546:859-867. CrossRef Medline

Béique JC, Lin DT, Kang MG, Aizawa H, Takamiya K, Huganir RL (2006) Synapse-specific regulation of AMPA receptor function by PSD-95. Proc Natl Acad Sci U S A 103:19535-19540. CrossRef Medline

Carlisle HJ, Fink AE, Grant SG, O’Dell TJ (2008) Opposing effects of PSD-93 and PSD-95 on long-term potentiation and spike timingdependent plasticity. J Physiol 586:5885-5900. CrossRef Medline

Chen L, Chetkovich DM, Petralia RS, Sweeney NT, Kawasaki Y, Wenthold RJ, Bredt DS, Nicoll RA (2000) Stargazin regulates synaptic targeting of AMPA receptors by two distinct mechanisms. Nature 408:936-943. CrossRef Medline

Chen X, Vinade L, Leapman RD, Petersen JD, Nakagawa T, Phillips TM, Sheng M, Reese TS (2005) Mass of the postsynaptic density and enu- meration of three key molecules. Proc Natl Acad Sci U S A 102: 11551-11556. CrossRef Medline

Cheng D, Hoogenraad CC, Rush J, Ramm E, Schlager MA, Duong DM, Xu P, Wijayawardana SR, Hanfelt J, Nakagawa T, Sheng M, Peng J (2006) Relative and absolute quantification of postsynaptic density proteome isolated from rat forebrain and cerebellum. Mol Cell Proteomics 5:11581170. CrossRef Medline

Chetkovich DM, Bunn RC, Kuo SH, Kawasaki Y, Kohwi M, Bredt DS (2002) Postsynaptic targeting of alternative postsynaptic density- 95 isoforms by distinct mechanisms. J Neurosci 22:6415-6425. Medline

Cho KO, Hunt CA, Kennedy MB (1992) The rat brain postsynaptic density fraction contains a homolog of the Drosophila discs-large tumor suppressor protein. Neuron 9:929-942. CrossRef Medline

Colledge M, Snyder EM, Crozier RA, Soderling JA, Jin Y, Langeberg LK, Lu H, Bear MF, Scott JD (2003) Ubiquitination regulates PSD-95 degradation and AMPA receptor surface expression. Neuron 40:595-607. CrossRef Medline

Craven SE, El-Husseini AE, Bredt DS (1999) Synaptic targeting of the postsynaptic density protein PSD-95 mediated by lipid and protein motifs. Neuron 22:497-509. CrossRef Medline

Cuthbert PC, Stanford LE, Coba MP, Ainge JA, Fink AE, Opazo P, Delgado JY, Komiyama NH, O’Dell TJ, Grant SG (2007) Synapse-associated protein $102 / \mathrm{dlgh} 3$ couples the NMDA receptor to specific plasticity pathways and learning strategies. J Neurosci 27:2673-2682. CrossRef Medline

Dakoji S, Tomita S, Karimzadegan S, Nicoll RA, Bredt DS (2003) Interaction of transmembrane AMPA receptor regulatory proteins with multiple membrane associated guanylate kinases. Neuropharmacology 45:849856. CrossRef Medline

Dosemeci A, Makusky AJ, Jankowska-Stephens E, Yang X, Slotta DJ, Markey SP (2007) Composition of the synaptic PSD-95 complex. Mol Cell Proteomics 6:1749-1760. CrossRef Medline

Ehlers MD (2003) Activity level controls postsynaptic composition and signaling via the ubiquitin-proteasome system. Nat Neurosci 6:231-242. CrossRef Medline

Ehrlich I, Malinow R (2004) Postsynaptic density 95 controls AMPA receptor incorporation during long-term potentiation and experience-driven synaptic plasticity. J Neurosci 24:916-927. CrossRef Medline

Ehrlich I, Klein M, Rumpel S, Malinow R (2007) PSD-95 is required for activity-driven synapse stabilization. Proc Natl Acad Sci U S A 104:41764181. CrossRef Medline

El-Husseini AE, Schnell E, Chetkovich DM, Nicoll RA, Bredt DS (2000) PSD-95 involvement in maturation of excitatory synapses. Science 290: 1364-1368. CrossRef Medline

Elias GM, Nicoll RA (2007) Synaptic trafficking of glutamate receptors by MAGUK scaffolding proteins. Trends Cell Biol 17:343-352. CrossRef Medline

Elias GM, Funke L, Stein V, Grant SG, Bredt DS, Nicoll RA (2006) Synapsespecific and developmentally regulated targeting of AMPA receptors by a family of MAGUK scaffolding proteins. Neuron 52:307-320. CrossRef Medline

Garcia EP, Mehta S, Blair LA, Wells DG, Shang J, Fukushima T, Fallon JR, Garner CC, Marshall J (1998) SAP90 binds and clusters kainate receptors causing incomplete desensitization. Neuron 21:727-739. CrossRef Medline

Hayashi MK, Tang C, Verpelli C, Narayanan R, Stearns MH, Xu RM, Li H, Sala C, Hayashi Y (2009) The postsynaptic density proteins Homer and Shank form a polymeric network structure. Cell 137:159-171. CrossRef Medline

Huettner JE, Baughman RW (1986) Primary culture of identified neurons from the visual cortex of postnatal rats. J Neurosci 6:3044-3060. Medline

Irie M, Hata Y, Takeuchi M, Ichtchenko K, Toyoda A, Hirao K, Takai Y, Rosahl TW, Südhof TC (1997) Binding of neuroligins to PSD-95. Science 277:1511-1515. CrossRef Medline

Jo J, Son GH, Winters BL, Kim MJ, Whitcomb DJ, Dickinson BA, Lee YB, Futai K, Amici M, Sheng M, Collingridge GL, Cho K (2010) Muscarinic receptors induce LTD of NMDAR EPSCs via a mechanism involving hippocalcin, AP2 and PSD-95. Nat Neurosci 13:1216-1224. CrossRef Medline

Kerchner GA, Nicoll RA (2008) Silent synapses and the emergence of a postsynaptic mechanism for LTP. Nat Rev Neurosci 9:813-825. CrossRef Medline 
Kim E, Sheng M (2004) PDZ domain proteins of synapses. Nat Rev Neurosci 5:771-781. CrossRef Medline

Kim E, Niethammer M, Rothschild A, Jan YN, Sheng M (1995) Clustering of Shaker-type $\mathrm{K}^{+}$channels by interaction with a family of membraneassociated guanylate kinases. Nature 378:85-88. CrossRef Medline

Kim E, Naisbitt S, Hsueh YP, Rao A, Rothschild A, Craig AM, Sheng M (1997) GKAP, a novel synaptic protein that interacts with the guanylate kinase-like domain of the PSD-95/SAP90 family of channel clustering molecules. J Cell Biol 136:669-678. CrossRef Medline

Kornau HC, Schenker LT, Kennedy MB, Seeburg PH (1995) Domain interaction between NMDA receptor subunits and the postsynaptic density protein PSD-95. Science 269:1737-1740. CrossRef Medline

Kuriu T, Inoue A, Bito H, Sobue K, Okabe S (2006) Differential control of postsynaptic density scaffolds via actin-dependent and -independent mechanisms. J Neurosci 26:7693-7706. CrossRef Medline

Long JF, Tochio H, Wang P, Fan JS, Sala C, Niethammer M, Sheng M, Zhang M (2003) Supramodular structure and synergistic target binding of the N-terminal tandem PDZ domains of PSD-95. J Mol Biol 327:203-214. CrossRef Medline

Malenka RC, Bear MF (2004) LTP and LTD: an embarrassment of riches. Neuron 44:5-21. CrossRef Medline

Masuko N, Makino K, Kuwahara H, Fukunaga K, Sudo T, Araki N, Yamamoto H, Yamada Y, Miyamoto E, Saya H (1999) Interaction of NE-dlg/SAP102, a neuronal and endocrine tissue-specific membraneassociated guanylate kinase protein, with calmodulin and PSD-95/SAP90. A possible regulatory role in molecular clustering at synaptic sites. J Biol Chem 274:5782-5790. CrossRef Medline

McGee AW, Dakoji SR, Olsen O, Bredt DS, Lim WA, Prehoda KE (2001a) Structure of the SH3-guanylate kinase module from PSD-95 suggests a mechanism for regulated assembly of MAGUK scaffolding proteins. Mol Cell 8:1291-1301. CrossRef Medline

McGee AW, Topinka JR, Hashimoto K, Petralia RS, Kakizawa S, AguileraMoreno A, Wenthold RJ, Kano M, Bredt DS, Kauer F (2001b) PSD-93 knock-out mice reveal that neuronal MAGUKs are not required for development or function of parallel fiber synapses in cerebellum. J Neurosci 21:3085-3091. Medline

Migaud M, Charlesworth P, Dempster M, Webster LC, Watabe AM, Makhinson M, He Y, Ramsay MF, Morris RG, Morrison JH, O’Dell TJ, Grant SG (1998) Enhanced long-term potentiation and impaired learning in mice with mutant postsynaptic density-95 protein. Nature 396:433-439. CrossRef Medline

Nakagawa T, Futai K, Lashuel HA, Lo I, Okamoto K, Walz T, Hayashi Y, Sheng M (2004) Quaternary structure, protein dynamics, and synaptic function of SAP97 controlled by L27 domain interactions. Neuron 44: 453-467. CrossRef Medline

Neves G, Cooke SF, Bliss TV (2008) Synaptic plasticity, memory and the hippocampus: a neural network approach to causality. Nat Rev Neurosci 9:65-75. CrossRef Medline

Niethammer M, Valtschanoff JG, Kapoor TM, Allison DW, Weinberg RJ,
Craig AM, Sheng M (1998) CRIPT, a novel postsynaptic protein that binds to the third PDZ domain of PSD-95/SAP90. Neuron 20:693-707. CrossRef Medline

Peng J, Kim MJ, Cheng D, Duong DM, Gygi SP, Sheng M (2004) Semiquantitative proteomic analysis of rat forebrain postsynaptic density fractions by mass spectrometry. J Biol Chem 279:21003-21011. CrossRef Medline

Prange O, Murphy TH (2001) Modular transport of postsynaptic density-95 clusters and association with stable spine precursors during early development of cortical neurons. J Neurosci 21:9325-9333. Medline

Sans N, Petralia RS, Wang YX, Blahos J 2nd, Hell JW, Wenthold RJ (2000) A developmental change in NMDA receptor-associated proteins at hippocampal synapses. J Neurosci 20:1260-1271. Medline

Schlüter OM, Schnell E, Verhage M, Tzonopoulos T, Nicoll RA, Janz R, Malenka RC, Geppert M, Südhof TC (1999) Rabphilin knock-out mice reveal that rabphilin is not required for rab3 function in regulating neurotransmitter release. J Neurosci 19:5834-5846. Medline

Schlüter OM, Xu W, Malenka RC (2006) Alternative N-terminal domains of PSD-95 and SAP97 govern activity-dependent regulation of synaptic AMPA receptor function. Neuron 51:99-111. CrossRef Medline

Schnell E, Sizemore M, Karimzadegan S, Chen L, Bredt DS, Nicoll RA (2002) Direct interactions between PSD-95 and stargazin control synaptic AMPA receptor number. Proc Natl Acad Sci U S A 99:13902-13907. CrossRef Medline

Stegmeier F, Hu G, Rickles RJ, Hannon GJ, Elledge SJ (2005) A lentiviral microRNA-based system for single-copy polymerase II-regulated RNA interference in mammalian cells. Proc Natl Acad Sci U S A 102: 13212-13217. CrossRef Medline

Sumioka A, Brown TE, Kato AS, Bredt DS, Kauer JA, Tomita S (2011) PDZ binding of TARP $\gamma-8$ controls synaptic transmission but not synaptic plasticity. Nat Neurosci 14:1410-1412. CrossRef Medline

Takeuchi M, Hata Y, Hirao K, Toyoda A, Irie M, Takai Y (1997) SAPAPs. A family of PSD-95/SAP90-associated proteins localized at postsynaptic density. J Biol Chem 272:11943-11951. CrossRef Medline

Valtschanoff JG, Weinberg RJ (2001) Laminar organization of the NMDA receptor complex within the postsynaptic density. J Neurosci 21:1211-1217. Medline

Xu W (2011) PSD-95-like membrane associated guanylate kinases (PSDMAGUKs) and synaptic plasticity. Curr Opin Neurobiol 21:306-312. CrossRef Medline

Xu W, Schlüter OM, Steiner P, Czervionke BL, Sabatini B, Malenka RC (2008) Molecular dissociation of the role of PSD-95 in regulating synaptic strength and LTD. Neuron 57:248-262. CrossRef Medline

Yao WD, Gainetdinov RR, Arbuckle MI, Sotnikova TD, Cyr M, Beaulieu JM, Torres GE, Grant SG, Caron MG (2004) Identification of PSD-95 as a regulator of dopamine-mediated synaptic and behavioral plasticity. Neuron 41:625-638. CrossRef Medline

Yoshii A, Sheng MH, Constantine-Paton M (2003) Eye opening induces a rapid dendritic localization of PSD-95 in central visual neurons. Proc Nat Acad Sci U S A 100:1334-1339. CrossRef Medline 